\title{
Evolution of Dynamic and Thermodynamic Structures before and during Rapid Intensification of Tropical Cyclones: Sensitivity to Vertical Wind Shear
}

\author{
DANDAN TAO AND FUQING ZHANG \\ Department of Meteorology and Atmospheric Science, and Center for Advanced Data Assimilation and \\ Predictability Techniques, The Pennsylvania State University, University Park, Pennsylvania
}

(Manuscript received 13 May 2018, in final form 21 January 2019)

\begin{abstract}
This study explores the spatial and temporal changes in tropical cyclone (TC) thermodynamic and dynamic structures before, near, and during rapid intensification (RI) under different vertical wind shear conditions through four sets of convection-permitting ensemble simulations. A composite analysis of TC structural evolution is performed by matching the RI onset time of each member. Without background flow, the axisymmetric TC undergoes a gradual strengthening of the inner-core vorticity and warm core throughout the simulation. In the presence of moderate environmental shear $\left(5-6 \mathrm{~m} \mathrm{~s}^{-1}\right)$, both the location and magnitude of the asymmetries in boundary layer radial flow, relative humidity, and vertical motion evolve with the tilt vector throughout the simulation. A budget analysis indicates that tilting is crucial to maintaining the midlevel vortex while stretching and vertical advection are responsible for the upper-level vorticity generation before RI when strong asymmetries arise. Two warm anomalies are observed before the RI onset when the vortex column is tilted. When approaching the RI onset, these two warm anomalies gradually merge into one. Overall, the most symmetric vortex structure is found near the RI onset. Moderately sheared TCs experience an adjustment period from a highly asymmetric structure with updrafts concentrated at the down-tilt side before RI to a more axisymmetric structure during RI as the eyewall updrafts develop. This adjustment period near the RI onset, however, is found to be the least active period for deep convection. TC development under a smaller environmental shear $\left(2.5 \mathrm{~m} \mathrm{~s}^{-1}\right)$ condition displays an intermediate evolution between ensemble experiments with no background flow and with moderate shear $\left(5-6 \mathrm{~m} \mathrm{~s}^{-1}\right)$.
\end{abstract}

\section{Introduction}

The rapid intensification (RI) of tropical cyclones (TCs) has long been an important issue in weather forecasting, not only for its profound impact on coastal life, but also for its difficulties in prediction. The timing of RI onset is especially difficult and is one of the biggest challenges for modelers and forecasters (Elsberry et al. 2007; Zhang et al. 2014). There have been many studies focusing on both external and internal factors leading to RI onset. Environmental influences like vertical wind shear (Rappin and Nolan 2012; Zhang and Tao 2013; Shu et al. 2014; Munsell et al. 2017), midlevel dry air (Tang and Emanuel 2010; Braun et al. 2012; Alland et al. 2017), and sea surface temperature (Nolan and Rappin 2008; Tao and Zhang 2014, hereafter TZ14) are among the most studied. By analyzing the differences between RI and other intensity change cases, Hendricks et al. (2010) found that

Corresponding author: Fuqing Zhang, fzhang@psu.edu the rate of intensification is weakly dependent on sea surface temperature. They found that RI is favored by weak deep-layer shear in the Atlantic Ocean and large conditional instability over the northwest Pacific. RiosBerrios and Torn (2017) had similar findings that vertical wind shear is not a dominant factor of RI onset. Studies suggest that these environmental factors are not what determine the occurrence of RI, which is more connected to TC's internal processes and conditions.

Though vertical wind shear may not be the primary factor that controls RI, it is well known that ambient vertical wind shear modulates convection and causes great asymmetry in TC structure. The inner-core structure of TC under vertical wind shear after RI onset has been explored by many studies. Black et al. (2002) documented the structure of a quasi-steady asymmetric TC in the presence of vertical wind shear. They found that strong updrafts at low levels are mainly located toward the downshear side of the inner core, which are then advected by the tangential wind of the primary TC circulation to the 
left of shear during their upward motion. These updrafts dissipate eventually toward the upshear side. Reasor et al. (2013) confirms this feature of downshear-right convective initiation and downshear-left precipitation maximum by analyzing the airborne Doppler radar measurements, in which they found the motion influence is secondary to the shear effect. DeHart et al. (2014) also constructed the structure of vertical motion and reflectivity in a shearrelative coordinate from airborne Doppler radar data, which again confirms the structure presented by Black et al. (2002). Zhang et al. (2013) and Nguyen et al. (2017) presented similar observation of this downshear-left preference of convections as well. These data analyses provide observations of the fine structures of TC inner cores under vertical wind shear. However, a disadvantage of these observational studies is the spatial and temporal limits in the available measurement data.

All the TC cases studied by the aforementioned papers are already at hurricane strength and mostly after the completion of precession, which cannot provide more information on TC's RI-related structural evolution and the corresponding dynamic and thermodynamic processes. From many previous studies (e.g., Rappin and Nolan 2012; Zhang and Tao 2013; Stevenson et al. 2014; Finocchio et al. 2016), it has been shown that there is a precession process before TC reaches a quasi-steady state mentioned above. This process is time evolving and has a dramatic change in the TC convective structure. Using satellite data that are more continuous in time and space, Harnos and Nesbitt (2011) reported that a convective ring structure forms before RI under low shear. Tao and Jiang (2015) utilized Tropical Rainfall Measuring Mission (TRMM) Precipitation Radar (PR) data to distinguish TC precipitation distribution and strength at different intensification rates. They found that the RI initiation is associated with increased and widespread shallow convection, while deep convection observed during RI is likely a response to the changes in the vortex. Although satellite data have better spatial and temporal continuity, the fine structure of TCs is still difficult to obtain from these observations.

Case studies using numerical models that produce spatially and temporally continuous simulations can be used to aid the observational studies. The thermodynamic structure of TCs relative to RI onset was studied by Chen and Zhang (2013), Chen and Gopalakrishnan (2015), and Judt and Chen (2016). They found a midlevel warm anomaly above the surface vortex center prior to RI onset, while upper-level warming can be found during the RI. Chen and Gopalakrishnan (2015) also emphasized the importance of the horizontal advection of convectiongenerated upper-level warming by the storm circulation in enhancing the upper-level warming above the surface center. Though Judt and Chen (2016) and Chen and
Gopalakrishnan (2015) analyzed the time evolution of the warm-core structure, a systematic study of the threedimensional structure and its sensitivity to vertical wind shear is yet to be completed.

Previous studies on RI using idealized simulations either focused on TC's entire life cycle with no background flow and a homogeneous environment (e.g., Nolan 2007; Miyamoto and Takemi 2015) where the persistent effects of shear on RI are excluded, or used a really intense vortex (e.g., Riemer et al. 2010) that does not well represent the TCs that undergo their first RI. In this study, we combine the benefits from using an asymmetric environment and using an idealized simulation to study TC structure relative to its first RI onset (or cyclogenesis for some cases). The benefit of using an idealized simulation is that one can impose multiple background flow conditions while fixing all other factors in a simulation to study in particular the dependence of RI onset on background flows. For example, Miyamoto and Nolan (2018) recently used a set of idealized ensemble simulations to examine the variations in TC intensity, size, radius of maximum wind (RMW) contraction, axisymmetrization process, and RI onset under varying vertical wind shear. However, they did not explore the TC structure in detail. In our previous study, TZ14, we analyzed the sheared TC evolution from an ensemble-mean perspective using the Eulerian composite at the same simulation time. We showed by comparing TC composites with different shear magnitudes that TC vortex responds to shear quickly by increasing its tilt magnitude. The vastly different RI onset timing results from a positive feedback between moist convection and the mean TC vortex under different shear conditions during precession. TZ14 mainly focuses on the period when TC vortex tilts to the downshear left quadrant.

The current study seeks to further uncover changes in TC structures after the tilt vector overcomes the drifting effect by the shear in the downshear-left quadrant. The analyses of the shear-induced asymmetry and its corresponding dynamic and thermodynamic processes are relative to the RI onset time. We conducted four sets of 20-member ensemble simulations under different background shear conditions. Composites of TC evolution are obtained by aligning the RI onset time as the reference time ${ }^{1}$ and taking the ensemble average. In this way, the common features in the evolution of TC vortices approaching RI onset can be identified from these composites in each set of

\footnotetext{
${ }^{1}$ The reference time is noted $t_{\mathrm{RI}}=0 \mathrm{~h}$ in the "Lagrangian" time frame of reference; the period we are interested in is between $t_{\mathrm{RI}}-$ $48 \mathrm{~h}$ to $t_{\mathrm{RI}}+36 \mathrm{~h}$.
} 
ensembles with a certain shear. It helps reveal the key RI-related processes that are otherwise hard to identify from individual cases (Judt and Chen 2016; Munsell et al. 2017) or from a typical Eulerian-based composite as in TZ14. Besides looking at the snapshots at TC's different stages, we also present a more complete picture of the time evolution of the dynamic and thermodynamic structures of a sheared TC in this study.

Aside from numerical simulations, previous statistical studies showed that TCs can intensify at different rates and also start intensification from different base intensities (Yaukey 2014). The RI defined by the National Hurricane Center (NHC) glossary is "an increase in the maximum sustained winds of a TC of at least $30 \mathrm{kt}$ in a 24-h period," which represents the 95th percentile of all intensification rates in the Atlantic Ocean (Kaplan and DeMaria 2003). However, this definition does not necessarily reflect the related physical processes during an RI onset. In this study, we define RI onset as the start time that maximizes the following 24-h intensification in minimum sea level pressure. As will become clear, through matching the RI onset time, the new composite analysis allows more generalizable findings of RI onset.

This paper is organized as follows: section 2 describes the experimental design; section 3 provides an overview of the four sets of ensemble simulations used in this study; sections 4 and 5 analyze the dynamic and thermodynamic structures, respectively, and their time evolution; and finally, section 6 provides the conclusions and summary of this study.

\section{Experimental design}

Following TZ14, four sets of 20-member convectionpermitting ensemble simulations are studied here that include no background flow (NOFLOW), $2.5 \mathrm{~m} \mathrm{~s}^{-1}$ shear (SH2.5), $5 \mathrm{~m} \mathrm{~s}^{-1}$ shear (SH5), and $6 \mathrm{~m} \mathrm{~s}^{-1}$ shear (SH6), respectively. All simulations are under constant sea surface temperature of $27^{\circ} \mathrm{C}$. Point downscaling is used to add unidirectional westerly shears throughout the simulation times (Nolan 2011). The vertical profiles of the environmental flows for the four ensemble experiments are shown in Fig. 1 in TZ14. The simulations use the Weather Research and Forecasting (WRF) Model, version 3.1. The maximum surface wind speed of the initial modified Rankine vortex is $15 \mathrm{~m} \mathrm{~s}^{-1}$ at a $135-\mathrm{km}$ radius. The domain is on a doubly periodic $f$ plane $(f=5 \times$ $10^{-5} \mathrm{~s}^{-1}$ ) with background thermodynamics using the Dunion (2011) moist-tropical sounding. The ensemble members are created by applying 20 groups of moisture perturbations with magnitudes randomly selected from a uniform distribution of $(-0.5,0.5) \mathrm{g} \mathrm{kg}^{-1}$ to the initial mixing ratio fields throughout the innermost domain below $950 \mathrm{hPa}$. The domain sizes are $4320 \mathrm{~km} \times 4320 \mathrm{~km}$ (D1), $1440 \mathrm{~km} \times 1440 \mathrm{~km}(\mathrm{D} 2)$, and $720 \mathrm{~km} \times 720 \mathrm{~km}$ (D3) with horizontal resolution of 18,6 , and $2 \mathrm{~km}$, respectively. The simulations have 49 vertical levels with the model top at $10 \mathrm{hPa}$. Two-way nesting is applied in all experiments.

Since the purpose of this study is to highlight the storm processes and evolution near the RI onset, we selected the analysis period of $48 \mathrm{~h}$ before and $36 \mathrm{~h}$ after the RI onset. The three-dimensional composites of TC fields are derived from matching the surface center of each simulation at the same time under the RI onset reference timing.

\section{Overview of the four ensemble sets}

Figure 1 is the overview of the intensity evolution in the four ensemble sets. The RI onset times are marked using black dots. Each member in NOFLOW and SH2.5 has begun slow intensification before the RI onset. The spreads of the RI onset time in NOFLOW and $\mathrm{SH} 2.5$ are $12 \mathrm{~h}$ and $19 \mathrm{~h}$, respectively. SH5 and SH6 are typical cases for TCs under moderate shear with variations in the RI onset as much as $39 \mathrm{~h}$ and $69 \mathrm{~h}$, respectively. The intensities at the RI onset in these four sets range between $998-976 \mathrm{hPa}$ and $20-44 \mathrm{~m} \mathrm{~s}^{-1}$. No specific intensity is found to initiate the RI onset.

In terms of TC strength, the evolution of kinetic energy integrated within the cylinder of $200-\mathrm{km}$ radius and $10-\mathrm{km}$ height from each member in the RI-onsetrelated timeframe is shown in the first column of Fig. 2. This cylinder covers the main TC circulation by using the surface center. For moderately sheared TCs in SH5 and SH6, the total kinetic energy increases from $-48 \mathrm{~h}$ to $-12 \mathrm{~h}$ and has no change for about $10 \mathrm{~h}$ before the RI onset. From the RI onset until the end of intensification, the integrated kinetic energy is monotonically increasing with shear, which is different from the TC intensity in terms of peak $10-\mathrm{m}$ surface wind speed (Fig. 1).

The storm-scale integrated diabatic heating rate is shown in the middle column of Fig. 2. In NOFLOW, the diabatic heating rate steadily increases from -48 to $-12 \mathrm{~h}$ and then keeps rather stable from -12 to $36 \mathrm{~h}$. At the same time, the RI onset time is in the middle of the diabatic heating rate recovery ( -6 to $6 \mathrm{~h}$ ) after a clear drop from -12 to $-6 \mathrm{~h}$ in SH5 and SH6 (Figs. $2 \mathrm{~g}, \mathrm{~h}$ ). In SH2.5, there also exists a drop but is seen about $24 \mathrm{~h}$ earlier (Fig. 2f). By simply dividing the 6-h kinetic energy change by the 6-h integrated diabatic heating rate, the "efficiency" of the transformation from diabatic heating to kinetic energy (Figs. 2i-1) is maximized between $0-12 \mathrm{~h}$ in 

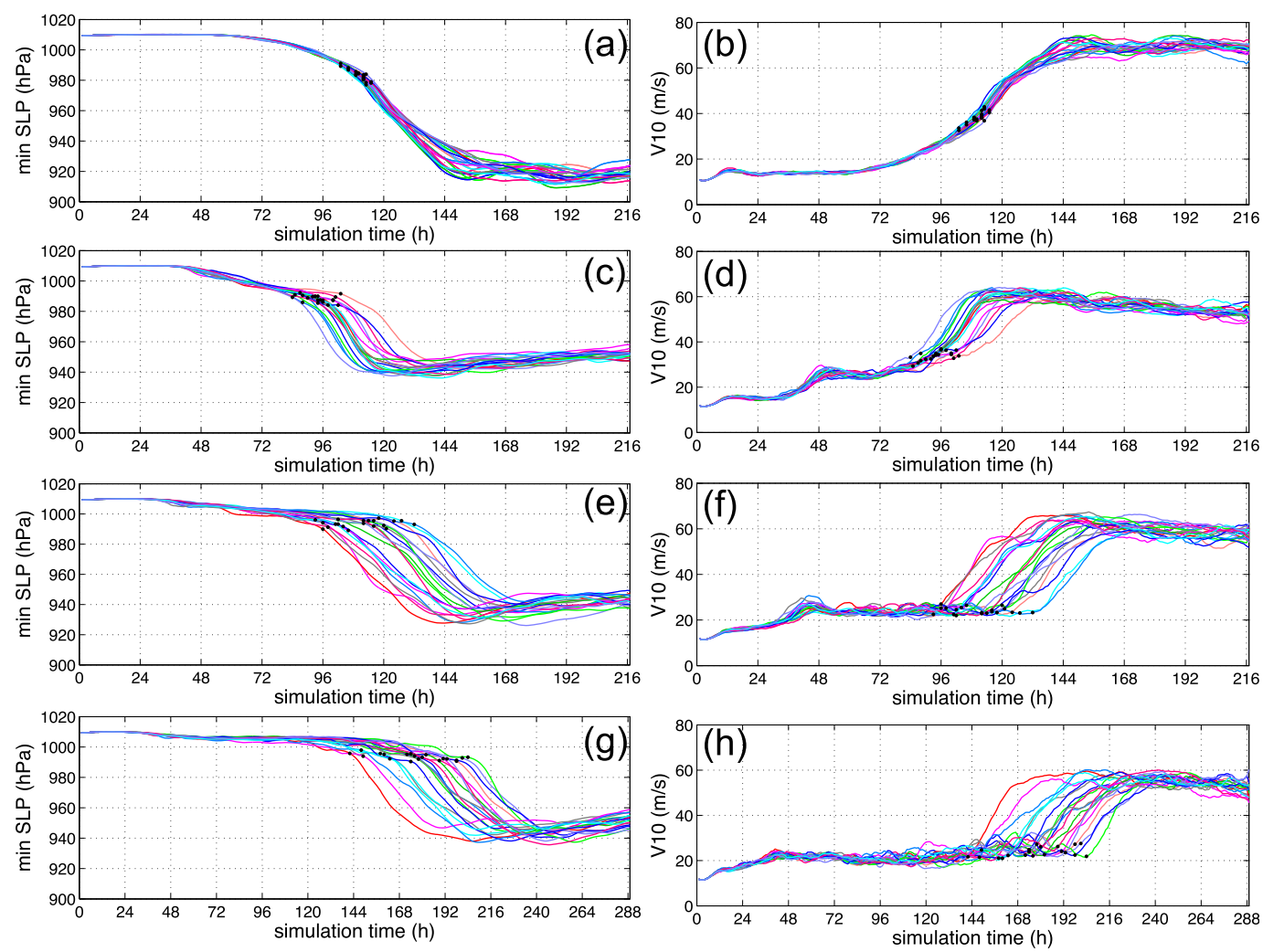

FIG. 1. The evolution of intensity in (left) minimum sea level pressure and (right) maximum 10-m total wind for (a),(b) NOFLOW; (c),(d) SH2.5; (e),(f) SH5; (g),(h) SH6. Different colors represent different members in each set.

Black dot indicates the RI onset time for each member.

all four sets, which indicates the RI process happens during the high efficiency period of energy transformation.

Through matching the RI onset of all members at $t_{\mathrm{RI}}=0 \mathrm{~h}$ (Fig. 3), the tilt evolution is colored according to the time relative to the RI onset times for $\mathrm{SH} 2.5$, SH5, and SH6. The tilt vector starts from the origin and ends on the line. For succinctness in the following sections, we define the direction of the tilt vector as down-tilt direction and the opposite direction of the tilt vector as up-tilt direction (similar to the definitions of downshear and upshear). All tilt evolutions exhibit a very smooth (no zigzags and no stagnancy) precession after the tilt vector passes the $90^{\circ}$ to the left of environmental shear and moves into the upshear-left quadrant. This is critical for further development of the TC vortex (TZ14, Stevenson et al. 2014) because the component of the shear "force" on tilt vector is toward the origin in the upshear-left quadrant, which can decrease the tilt magnitude. It is the opposite scenario in the downshear-left quadrant where the shear force on tilt vector directs away from the origin that can increase the tilt magnitude. The general difference between these three sets is mainly the tilt magnitude, the precession speed and the smoothness of the tilt evolutions in the downshear-left quadrant. The SH2.5 ensemble has much smaller tilt magnitude than SH5 and SH6 at $-12 \mathrm{~h}$ that the value is already decreased to about $10 \mathrm{~km}$. We also find that the RI onset time is not the steady end point for the precession process in SH5 and SH6. After RI, the precession still exists except that the tilt magnitude is smaller and the precession rate is faster. This continuing precession is similar to the dry dynamics of the vortex Rossby wave (VRW) damping described in Reasor et al. (2004), such that the vortices tend to achieve steady state tilt to the left of the vertical wind shear vector after several precession cycles instead of only one cycle. The dry dynamics, however, cannot explain why the tilt magnitude can reach such a small value $(<10 \mathrm{~km})$ within only one cycle of precession, which is considered to be the contribution of the moist convection as is described in Tao and Zhang (2015).

The four composite radii of maximum azimuthally averaged 10-m tangential wind (RMW) decrease continuously from -48 to $12 \mathrm{~h}$ and reach a similar final value after $12 \mathrm{~h}$ (Fig. 4a). The inner-core size of the surface vortex increases with shear magnitude, which is seen in Fig. 4a that SH6 has the largest RMW at all times. The RMW of SH2.5 is closer to that of NOFLOW from $-24 \mathrm{~h}$, 

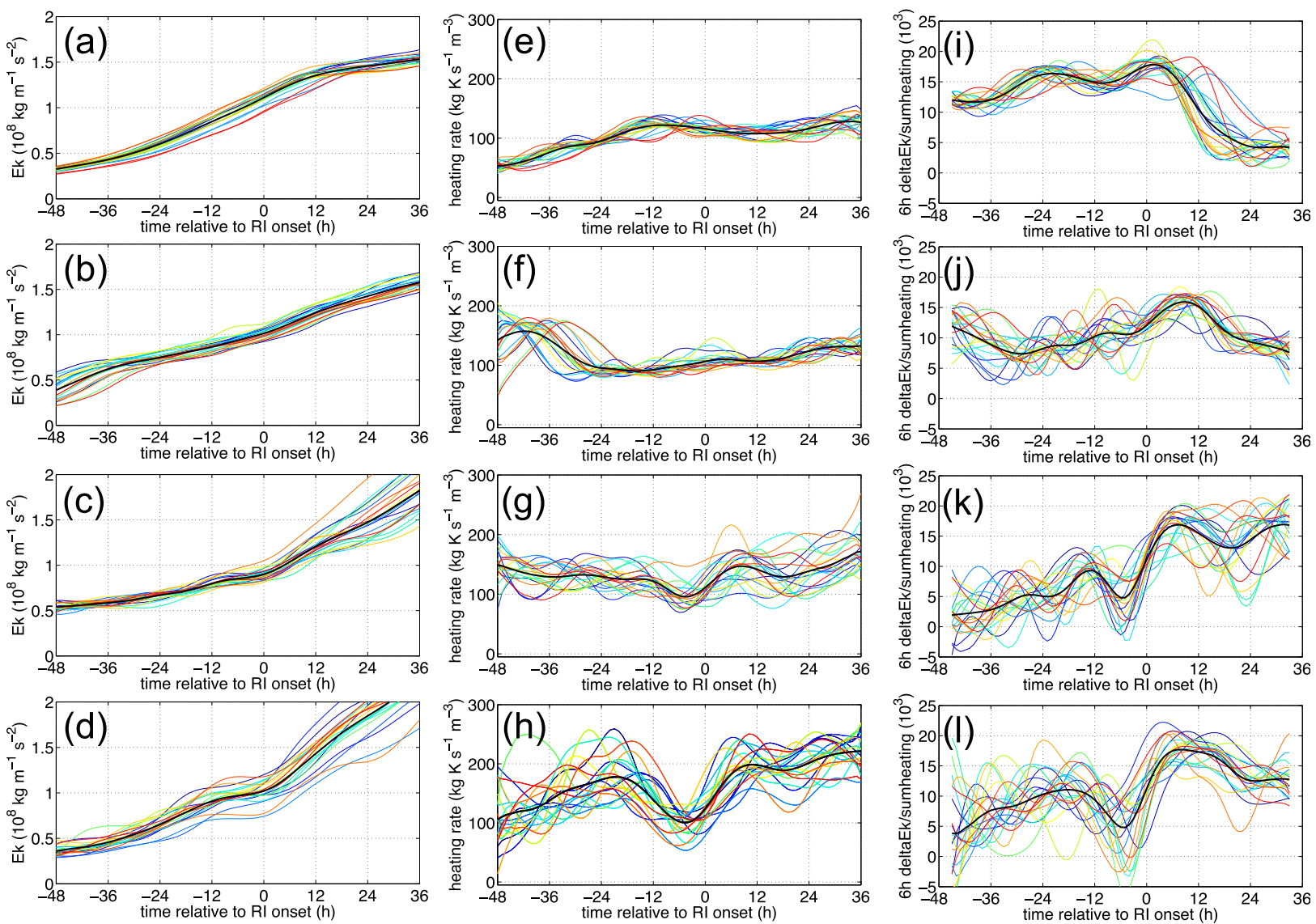

FIG. 2. Time evolution of (a)-(d) the total kinetic energy accumulated within 200-km radius below $10 \mathrm{~km}$ using the surface center; (e)-(h) the total diabatic heating accumulated within 200-km radius below $10 \mathrm{~km}$ using the surface center; and (i)-(l) the ratio of 6-h total kinetic energy difference to 6-h accumulated diabatic heating rate. (from top row to bottom row) NOFLOW, SH2.5, SH5, and SH6. Each colored line is one member; the thick black line is the ensemble mean.

and changes gradually afterward. The reduction of the RMWs in SH5 and SH6 is much greater during the $12 \mathrm{~h}$ after the RI onset than that in NOFLOW and SH2.5. To show the extent of vertical decoupling between the vortex inner cores at low and midlevels, we also did a comparison between the tilt magnitude and RMW. The ratio between the 450-850-hPa tilt and RMW (Fig. 4b) drops dramatically from -12 to $0 \mathrm{~h}$ and reaches minimum near the RI onset time in SH5 and SH6. In contrast, the SH2.5 case has rapid reduction in the ratio about $12 \mathrm{~h}$ earlier and continuous slow reduction from -12 to $12 \mathrm{~h}$, which also results in the slow intensification before the RI onset (Fig. 1d). During RI, this ratio maintains a nonzero value in the three sheared cases, but does not exceed 0.5.

From the overview of these four sets under different background flows, it is clear that SH5 and SH6 are grouped to represent the TCs under typical moderate shear magnitudes, while SH2.5 shares some similarity with both moderately sheared cases and the NOFLOW case. In all three sheared cases, the rapid reduction in the asymmetry is seen before the RI onset and the vortex is mostly aligned near the RI onset time.

\section{Evolution of dynamic structures}

The first dynamic field analyzed is the $10-\mathrm{m}$ total wind composite (Fig. 5). We selected the times of $-36,-12,-6$, 0 , and $12 \mathrm{~h}$ to display the structural changes, which are the most representative ones for a period. The wind field in NOFLOW has axisymmetric structure at all times (Figs. 5a-e). From -36 to $-12 \mathrm{~h}$, the wind field quickly spins up in NOFLOW that it expands radially outward and intensifies in the inner core. The wind fields in $\mathrm{SH} 2.5, \mathrm{SH} 5$, and $\mathrm{SH} 5$ exhibit strong asymmetry at $-36 \mathrm{~h}$ (Figs. 5f, 5k, and 5p) with the strongest winds located at the down-tilt-left side. On the down-tilt-right side, there also exists a locally stronger wind area, although weaker in magnitude than the down-tilt-left wind maximum. The wind asymmetry becomes less noticeable from $-12 \mathrm{~h}$ in SH2.5 due to the small tilt $(\sim 10 \mathrm{~km})$ and the significant 

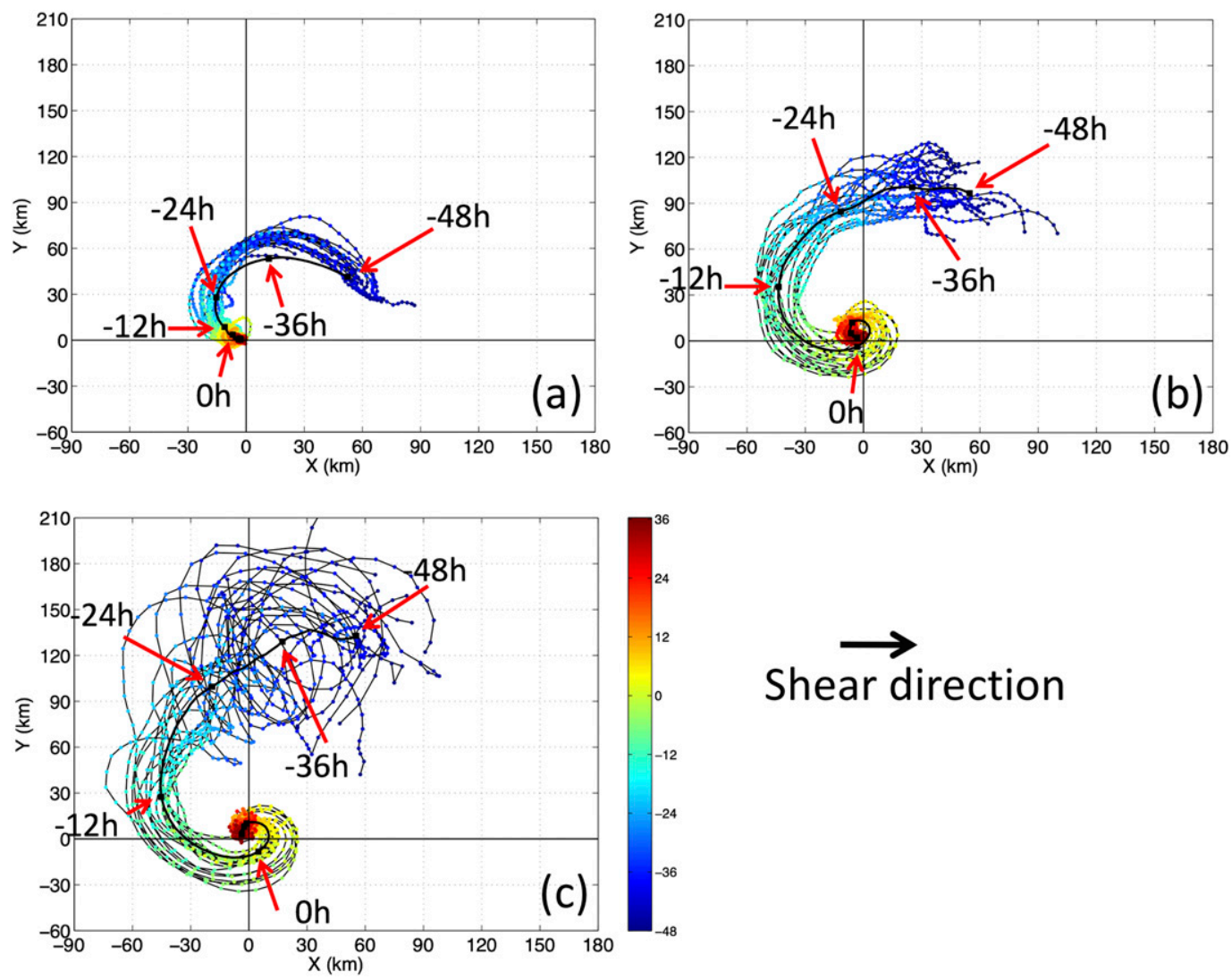

FIG. 3. Hourly $850-450$-hPa tilt evolution from $-48 \mathrm{~h}$ to $36 \mathrm{~h}$ relative to the RI onset. Each color means one time. The mean tilt evolution in each set is in black. The black dot on the black line indicates 12-h interval. (a) SH2.5, (b) SH5, and (c) SH6.

intensification in the inner-core wind field. After the RI onset, the $10-\mathrm{m}$ wind structure of $\mathrm{SH} 2.5$ is very close to that of NOFLOW. In SH5, from -36 to $-12 \mathrm{~h}$, the maximum $10-\mathrm{m}$ total wind area maintains the magnitude of about $19 \mathrm{~m} \mathrm{~s}^{-1}$, while the magnitude decreases to $\sim 17 \mathrm{~m} \mathrm{~s}^{-1}$ at the RI onset but quickly reintensifies to greater than $25 \mathrm{~m} \mathrm{~s}^{-1}$ after $12 \mathrm{~h}$ (Figs. $5 \mathrm{k}-\mathrm{O}$ ). The RMW, calculated from the azimuthally averaged $10-\mathrm{m}$ tangential wind, gives a good estimation of the inner-core size at all azimuth even in this highly asymmetric situation before RI starts. The asymmetry becomes less evident in the 10-m wind field after the RI onset. The evolution of the wind field in SH6 is quite similar to that in SH5 except for the larger size.

To show the evolution and extent of the slantwise vortex column as well as the corresponding structure of the vertical and horizontal wind fields, we also plotted vertical cross sections of absolute vorticity, total horizontal wind and vertical velocity in Fig. 6. The directions (red arrow in Fig. 5) used for the cross section of sheared composites are chosen to be across the surface center and along the direction of $450-850$-hPa tilt vectors. The selected cross sections can capture the most information of the tilted vortex column and the most prominent features of the main convection.

In NOFLOW, the vorticity field shows a bottom-up development (Figs. 6a-e). At $-36 \mathrm{~h}$, the convection generates a vorticity ring structure above the boundary layer. The $10 \mathrm{~m} \mathrm{~s}^{-1}$ total wind contour around the eye is slantwise at $-36 \mathrm{~h}$ but becomes more upright at later times. At the same time, the updraft and downdraft structures in NOFLOW are weak and less organized. After $-12 \mathrm{~h}$, the intensification of the NOFLOW wind field is mainly observed inside the $15 \mathrm{~m} \mathrm{~s}^{-1}$ contour, while the wind field outside the $15 \mathrm{~m} \mathrm{~s}^{-1}$ contour has almost no change afterward. From $-12 \mathrm{~h}$, the updrafts strengthen around the surface center to enable the stronger subsidence in the eye.

In $\mathrm{SH} 2.5$, the vortex column is mostly tilted between 3- and 7-km heights on the up-tilt side at - 36 h (Fig. 6f), while the upper-level vortex collocates with the strong convection above $7-\mathrm{km}$ height. The updrafts concentrate at the down-tilt side. At $-12 \mathrm{~h}$, the structure of the wind field becomes more symmetric and the vortex column is 
(a) RMW

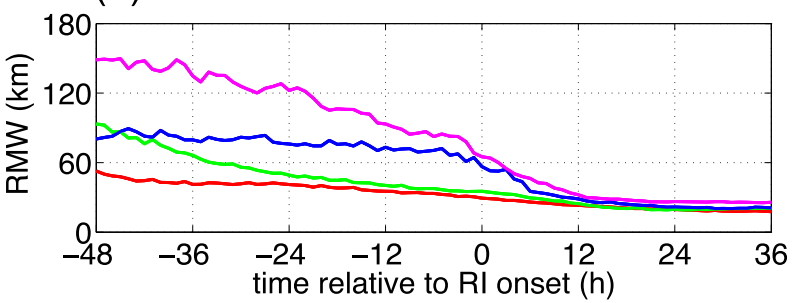

(b) Tilt/RMW

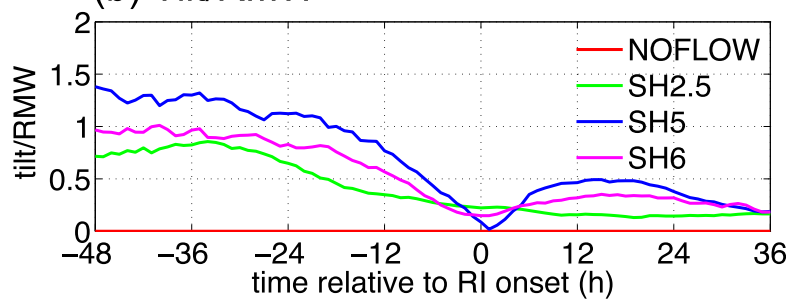

FIG. 4. Time series of (a) RMW and (b) ratio between 450-850-hPa tilt magnitude and RMW.

slightly tilted. The $15 \mathrm{~m} \mathrm{~s}^{-1}$ wind contour expands more outward to the radius of $230 \mathrm{~km}$ on the down-tilt side and less to the $150-\mathrm{km}$ radius on the up-tilt side. From $-6 \mathrm{~h}$, updrafts start to occur on the up-tilt side above $10-\mathrm{km}$ height and the high-level subsidence in the eye emerges. From the RI onset, the inner core spins up quickly. Correspondingly, the updraft structure in the eyewall evolves similarly to NOFLOW but weaker on the up-tilt side. From -36 to $-12 \mathrm{~h}$, a significant intensification in the vortex column is observed though the vortex column is not fully aligned yet.

For SH5, the total wind field responds to the tilt of the TC vortex column (Figs. 6k-o). The structure of the wind field matches the tilt of the inner-core vortex well at all times. At -36 and $-12 \mathrm{~h}$, the asymmetric outflow region can be seen outside the $120-\mathrm{km}$ radius of the surface center and at the down-tilt side between 11- and $15-\mathrm{km}$ heights. During the last $6 \mathrm{~h}$ of axisymmetrization, the outflow greatly weakens due to the weakening convection. Consistent with $10-\mathrm{m}$ total wind plots (third row in Fig. 5), the outermost expansion of the lower-level total wind field is observed only before the RI onset, while during RI, the inner-core wind intensifies greatly with a wind expansion at middle to upper levels outside the $120-\mathrm{km}$ radius. This change results in the rapid strengthening of the entire vortex column vorticity and the penetration of the TC to even higher levels during RI. Similar to SH2.5, the vortex is mostly tilted between $3-$ and $7-\mathrm{km}$ heights at $-36 \mathrm{~h}$. When the time approaches the RI onset at $-6 \mathrm{~h}$, the vortex column becomes more upright. The downdrafts start to occur within the updrafts at comparable strength. Recall from Figs. $2 \mathrm{~g}$ and $2 \mathrm{~h}$, the diabatic heating rate reaches minimum value around $-6 \mathrm{~h}$, which corresponds to the reduction of convective activity as well as updrafts shown in Figs. $6 \mathrm{~m}$ and $6 \mathrm{r}$. At the RI onset, updrafts and downdrafts spread over the surface center. After $12 \mathrm{~h}$ of RI, the updrafts reach the up-tilt side at high levels with subsidence occurring in the eye. The updraft structure is configured to ensure descent within the eye and downdrafts outside the eyewall updrafts, though some asymmetry remains. The absolute vorticity at $-36 \mathrm{~h}$ shows that the TC inner-core vortex below $3-\mathrm{km}$ height is nearly vertical with the maximum vorticity just above the surface center. At the same time, the vortex between 3- and $7-\mathrm{km}$ heights is tilted away from the surface-based center but connecting to the upper-level vortex above 7-km height and collocated with the strongest convective updrafts at the down-tilt side. From -36 to $-12 \mathrm{~h}$, local amplification of the low-level vortex is seen with the strengthening of the mid- to upper-level vortices. The mid- to upper-level vorticity maximum starts to move within the $60-\mathrm{km}$ radius of the surface center, and begins to overlap with the surface-based low-level vortex from $-12 \mathrm{~h}$. Thereafter, the inner-core vorticity gains accelerated growth and axisymmetrization: the vortex is not only aligned at all vertical levels, but also intensifies greatly within the $60-\mathrm{km}$ radius.

SH6 is very close to SH5 that the upper-level vortex $(z>7 \mathrm{~km})$ is completely displaced from the surface vortex at $-36 \mathrm{~h}$. Because the convection of SH6 extends farther away from surface center at early times than that of SH5, the wind field at down-tilt side and large radii is stronger than that in SH5. This feature maintains the strength of the wind field at large radii at all levels even after its RI onset.

The collocation of the mid- to upper-level vortices with the updrafts when the vortex is highly asymmetric suggests that deep convection plays a critical role in maintaining the strength of the mid- to upper-level vortices. A vorticity budget analysis is carried out between $z=5-7 \mathrm{~km}$ and $z=7-9 \mathrm{~km}$ (Fig. 7) to check this critical role. The vorticity equation used here is the same as in Miyamoto and Nolan (2018):

$$
\begin{aligned}
\frac{\partial \zeta}{\partial t}= & -u \frac{\partial \zeta}{\partial x}-v \frac{\partial \zeta}{\partial y}-w \frac{\partial \zeta}{\partial z}+(\zeta+f) \frac{\partial w}{\partial z} \\
& -\frac{\partial v}{\partial z} \frac{\partial w}{\partial x}+\frac{\partial u}{\partial z} \frac{\partial w}{\partial y}+D_{\zeta},
\end{aligned}
$$

where $\zeta$ is the vertical component of the relative vorticity, $(u, v, w)$ are the velocities, and $f$ is the Coriolis parameter. The first three terms on the right-hand side are the advection terms, the fourth term is the stretching 

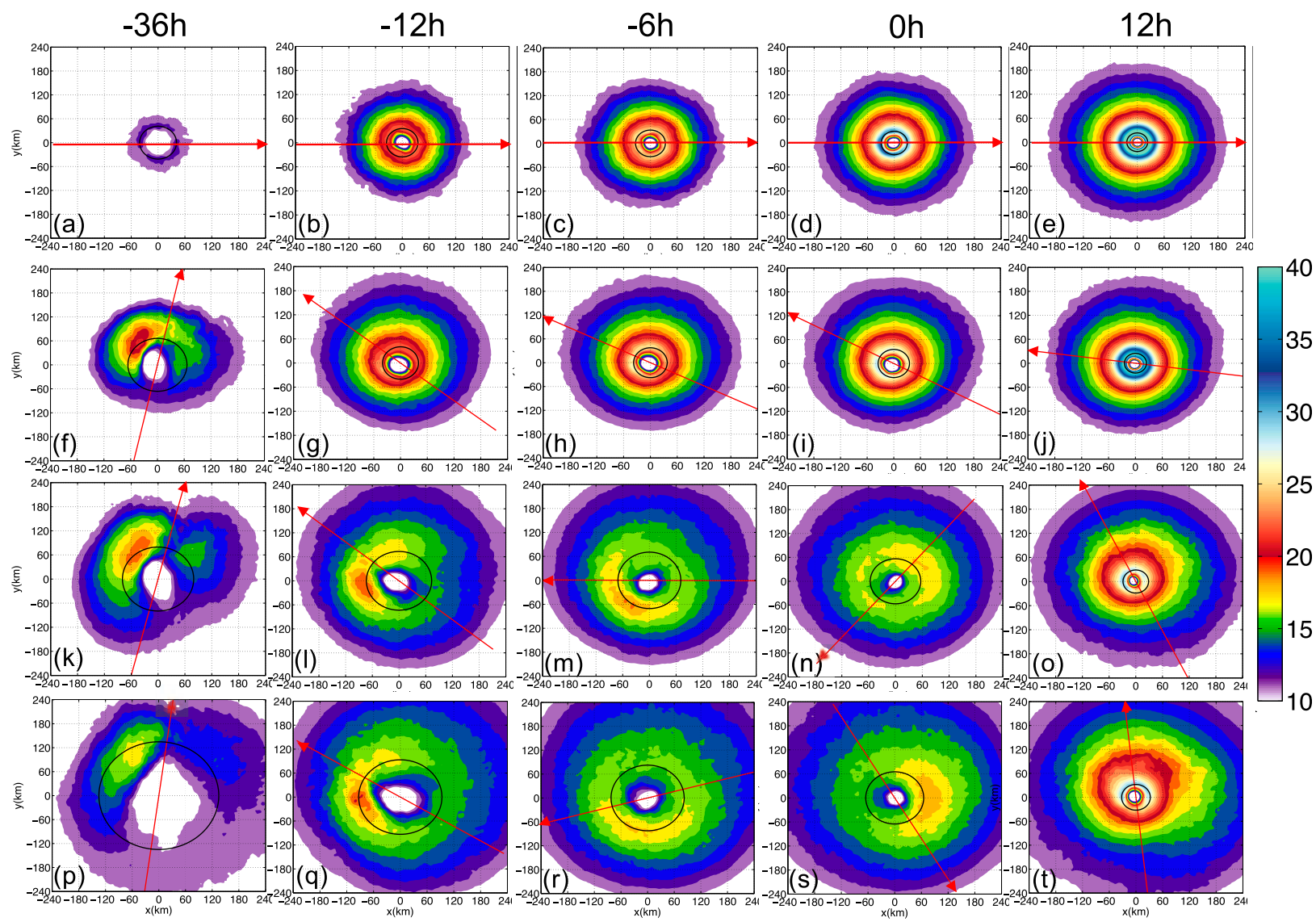

FIG. 5. Horizontal plots of 10-m total wind magnitude (shading) for (a)-(e) NOFLOW, (f)-(j) SH2.5, (k)-(o) SH5, and (p)-(t) SH6. Black circle means RMW. Red arrow indicates tilt direction as well as the vertical cross-sectional location in Figs. 6 and 12.

term, the fifth and sixth terms are the tilting terms, while the solenoidal and diffusion effects are in $D_{\zeta}$.

The time evolutions of the four vorticity budget terms (the horizontal advection, vertical advection, stretching, and tilting terms) are calculated. The terms are first calculated in Cartesian coordinates of each member. The terms are then averaged within a $50-\mathrm{km}$ radius and between $5-\mathrm{km}$ and $7-\mathrm{km}$ heights using the vorticity center location at the $6-\mathrm{km}$ height for the midlevel vortex, and averaged within a $50-\mathrm{km}$ radius and between 7- and 9-km heights using the vorticity center location at the $8-\mathrm{km}$ height for upper-level vortex. The $50-\mathrm{km}$ radius is selected to cover the vortex core area. Last, the terms are averaged among members of the same ensemble set using the RI onset time reference.

The calculation shows that the tilting term is positive for the midlevel vortices in sheared cases when there is significant asymmetry (Figs. 7b-d), which is consistent with the location of the updrafts (off the midlevel vortex center for sheared cases): the horizontal vorticity due to the vertical gradient of horizontal vortex wind is tilted by the updrafts that generates positive vertical vorticity.
The horizontal advection term is also positive and comparable to the tilting term in the three sheared cases. In these highly asymmetric scenarios, the vorticity generated by the updrafts at the down-tilt side is then advected by the tangential wind to the up-tilt side. Unlike NOFLOW, the tilting term decreases when time approaches the RI onset in the three sheared cases. This can partly be explained by the weakening updrafts at the same time and the updrafts spreading over the surface center that the asymmetry weakens. The negative terms are the stretching and vertical advection in all sheared cases especially in SH5 and SH6. The negative vertical advection term is due to the large tilt in SH5 and SH6 that the surface vortex core is not right under the mid- to upper-level vortex as a high vorticity source. The negative stretching term results from the dislocation of the maximum updrafts off the midlevel vortex center at the down-tilt side and the slightly slantwise updrafts. One thing worth mentioning is that the summation of the four terms of (1), as an instant tendency, is larger than the vorticity increment calculated from the hourly model output. Nevertheless, the summation of the four terms is 


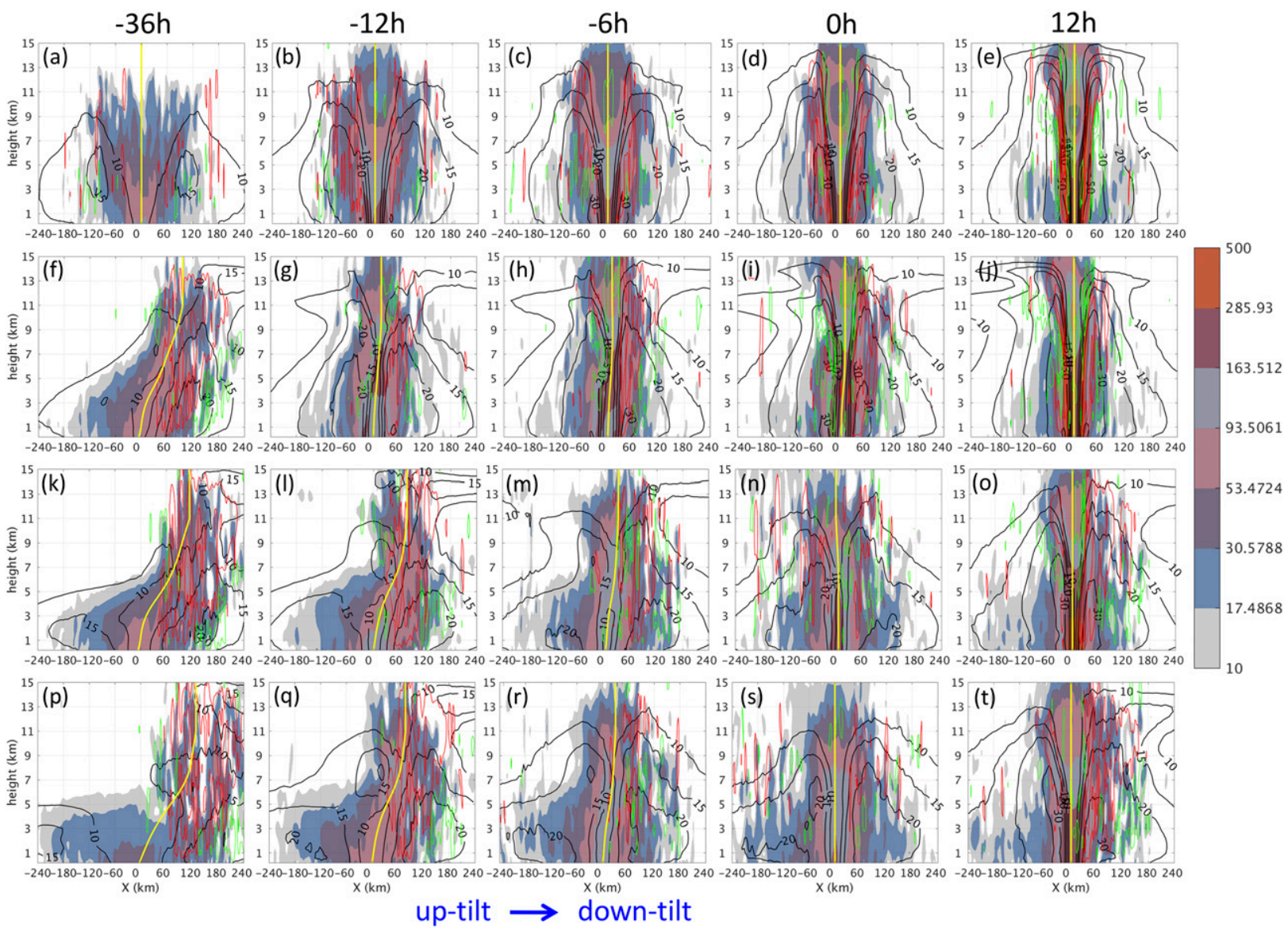

FIG. 6. Vertical cross-sectional plots of absolute vorticity (shading), vertical velocity (contours of $[-1-0.5-0.3-0.10 .313610] \mathrm{m} \mathrm{s}^{-1}$, updrafts in red, downdrafts in green) and horizontal wind magnitude (including both tangential wind and radial wind, black contours of [10 1520305060 ] $\mathrm{m} \mathrm{s}^{-1}$ ) along tilt direction for (a)-(e) NOFLOW, (f)-(j) SH2.5, (k)-(o) SH5, and (p)-(t) SH6. The times are - 36, -12, $-6,0$, and $12 \mathrm{~h}$. The yellow line is the approximate center line of the vortex column.

positive, which indicates positive contribution from convection-generated vorticity (tilting term) and redistribution by the horizontal wind (horizontal advection) that overcomes negative contribution from the divergence (stretching term) and the dilution (vertical advection).

For the upper-level vortices, the positive terms are quite different in NOFLOW/SH2.5 versus SH5/SH6. NOFLOW and $\mathrm{SH} 2.5$ have a positive tilting term, while SH5 and SH6 have a positive stretching term and a negative tilting term. During the period between $-6 \mathrm{~h}$ and the RI onset, the tilting and stretching magnitudes decrease to near zero in SH5/SH6. As shown in Figs. 6k and $6 p$, the collocation of the deep convection and the upper-level vortex in SH5/SH6 during the large tilt period between -36 and $-12 \mathrm{~h}$ ensures the negative contribution of the tilting term: the horizontal vorticity due to vertical gradient of the horizontal tangential wind is tilted by the updrafts maximized at the upper-level vortex center to generate negative vorticity. During the same period, the positive contribution of the stretching term results from updrafts that are maximized above the $7-\mathrm{km}$ height. The vertical advection term is also positive in SH5/SH6 because the midlevel vorticity is able to be advected by the updrafts to the upper level. From $-6 \mathrm{~h}$, the upper-level vortex centerline is at the left/up-tilt side of the updrafts in Figs. $6 \mathrm{~m}$ and $6 \mathrm{r}$, which indicate the decoupling of the convection and the upper-level vortex. The decoupling and weakening of the convection result in the decreasing magnitudes of all four budget terms (Figs. $7 \mathrm{~g}, \mathrm{~h}$ ). Nevertheless, the budget analysis indicates that when the vortex column is highly asymmetric, the deep convection is critical for the development of the midlevel vortex by tilting and upper-level vortex by stretching and vertical advection. The relative location of the updrafts to the vortex determines how convection contributes to the vortex intensification. 

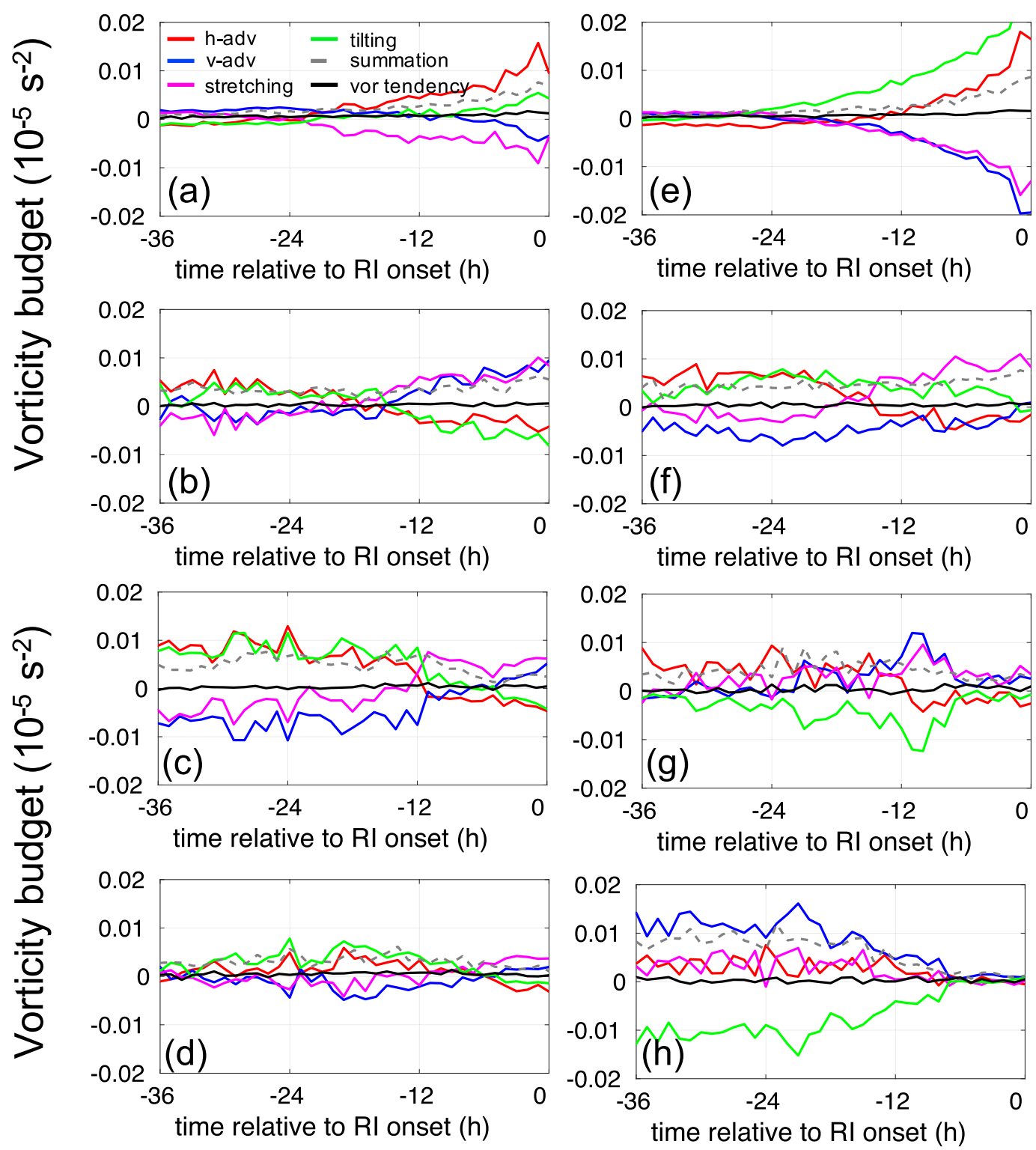

FIG. 7. (left) Vorticity budget terms for the midlevel vortex: averaged within a 50-km radius of the 6-km vortex center and between 5- and 7-km heights; (right) vorticity budget terms for the upper-level vortex: averaged within a 50-km radius of the 8-km vortex center and between 7-9-km height. (a),(e) NOFLOW; (b),(f) SH2.5; (c),(g) SH5; and (d),(h) SH6.

To further demonstrate the evolution of the surfacecenter-based inner-core strength and how the mid- to upper-level vortices evolve into the surface-based innercore region, the relative vorticity field averaged within the $50-\mathrm{km}$ radius of the surface center is shown in Fig. 8 . NOFLOW has a progressive development in the innercore vorticity that it builds up and strengthens gradually with time. At the RI onset, the vortex column has already intensified. The NOFLOW vortex reaches the $15-\mathrm{km}$ height during RI. The inner-core vorticity in SH2.5 evolves very similarly to that in NOFLOW. The inner-core vorticity for the column below $5 \mathrm{~km}$ starts to increase at very early time (around $-48 \mathrm{~h}$ ) (Fig. $8 \mathrm{~b}$ ). However, the development of vorticity above the $5-\mathrm{km}$ height slows down between -6 and $0 \mathrm{~h}$. After $0 \mathrm{~h}$, the upper-level vortex further intensifies. The early intensification before the RI onset in NOFLOW and SH2.5 is also due to the definition of RI onset used in this paper since NOFLOW and SH2.5 already start slow intensification before the RI onset time. SH5 is very different from both NOFLOW and $\mathrm{SH} 2.5$. The low-level inner-core vorticity strengthens slowly between -48 and $-12 \mathrm{~h}$. There is a sharp increase in 

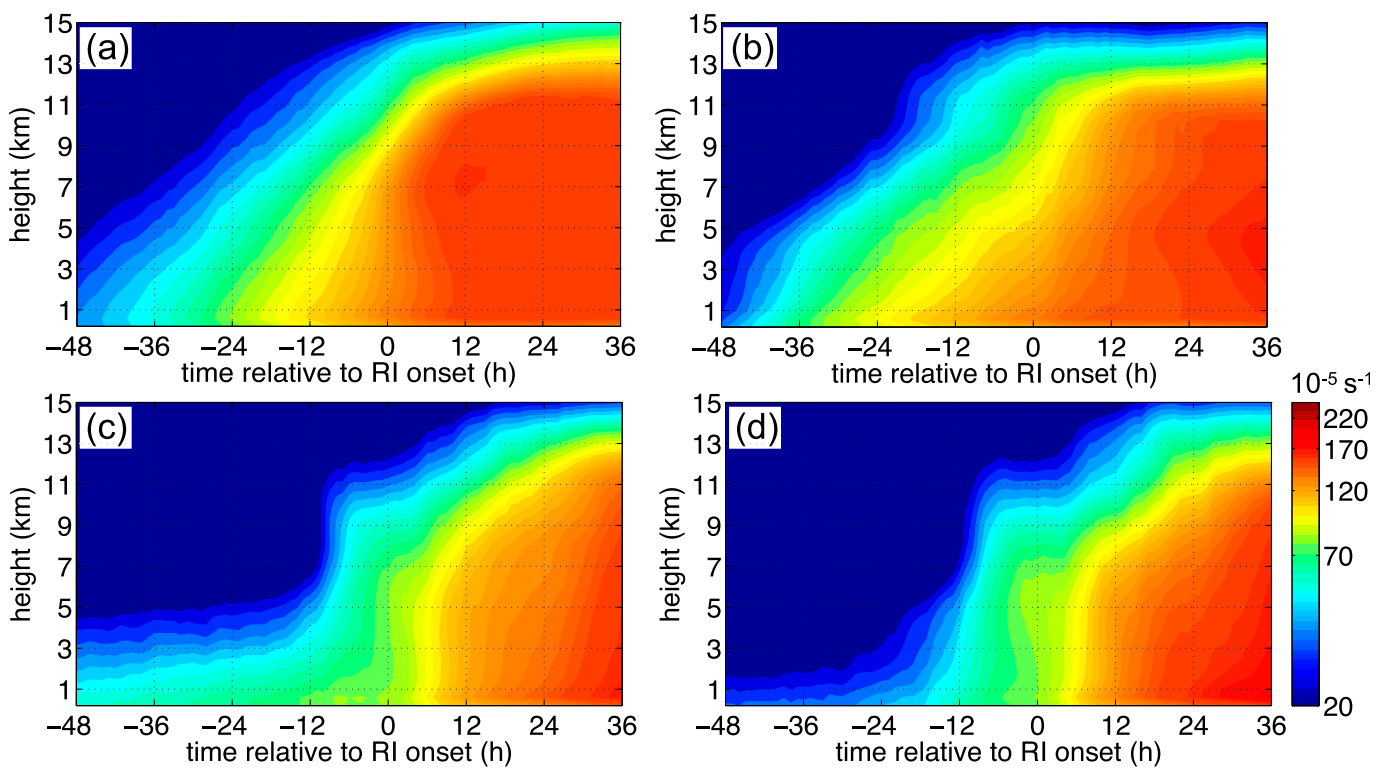

FIG. 8. Time-height plots for the vorticity averaged within 50-km radius of the surface center: (a) NOFLOW,

(b) SH2.5, (c) SH5, and (d) SH6.

the inner-core vorticity between $5-$ and $11-\mathrm{km}$ heights (Fig. 8c) $6 \mathrm{~h}$ before the RI onset. This sharp increase is consistent with Fig. 61 that the mid- to upper-level vortices start to move across the surface center at the same time around $12 \mathrm{~h}$ before the RI onset. At the RI onset, the vortex strength of SH5 is considerably weaker than that in NOFLOW and SH2.5. After $12 \mathrm{~h}$ of RI, the inner-core vorticity of SH5 further extends the whole column upward to almost $15 \mathrm{~km}$. SH6 shares some common features in the vortex dynamics with SH5 but has much weaker low-level vortex before $-12 \mathrm{~h}$.

From Figs. 5 and 6, it is clear that the vortex primary circulation structure evolves with the tilt vector. To further explore the structure of the secondary circulation besides the vertical wind in Fig. 6, we plotted the boundary layer radial flow evolution as a function of azimuth in Fig. 9. The annular region from RMW to $50 \mathrm{~km}$ outward is selected to study the inflow supply for the primary updraft. As expected, NOFLOW does not show a preferred azimuth of the boundary layer inflow. At $-48 \mathrm{~h}, \mathrm{SH} 2.5$ has a clear upshear outflow and downshear inflow structure, which evolves with the tilt vector and the outflow is gradually replaced by inflow after $-6 \mathrm{~h}$. In SH5 and SH6, the radial inflow region is initially located at both downshear quadrants, which gradually evolves cyclonically further upshear-left quadrant with time prior to the RI onset. The radial outflow is first located at the upshear quadrants and evolves cyclonically toward downshear right prior to the RI onset. During the precession before the RI onset, the asymmetry in the boundary layer radial flow is decreasing, however, because of the continuous precession after the first alignment referred to in section 2, the radial flow regains asymmetry after the RI onset. The contours of the equivalent potential temperature $\theta_{e}$ indicate that the boundary layer low $\theta_{e}$ locates at the down-wind side of the tilt vector before the RI onset, which represents the cold pool and the pathway of midlevel dryer air getting into the boundary layer by the downdrafts under strong asymmetric convection (Riemer et al. 2010). From Fig. 9, we can find that the radial flow pattern and low $\theta_{e}$ air in the boundary layer evolve with the tilt vector in SH5/SH6. This phenomenon can be explained by the relationship between the primary convection location and the vortex tilt. Since the radial inflow fuels into the convective updrafts and the low $\theta_{e}$ air comes from the convective downdrafts, the radial inflow and low $\theta_{e}$ patterns in the boundary layer are closely associated with the main convection cluster that is modulated by the vortex tilt.

To quantify the dominant asymmetry in the boundary layer radial flow, Fig. 10a shows the evolution of the wavenumber-1 amplitude of boundary layer radial wind. SH6 has the largest wavenumber-1 amplitude at all times but near the RI onset. In a few hours before the RI onset time, the wavenumber- 1 amplitudes reach minimum in SH5 and SH6 while the wavenumber-1 amplitude in $\mathrm{SH} 2.5$ achieves a local minimum but does not bounce back as much as that in SH5 and SH6. This figure is another interpretation of alignment near the RI onset like Fig. 4b. For better understanding the total boundary layer flow convergence, Fig. 10b is the total radial mass flux at $200-\mathrm{km}$ radius and below $2 \mathrm{~km}$, which roughly 

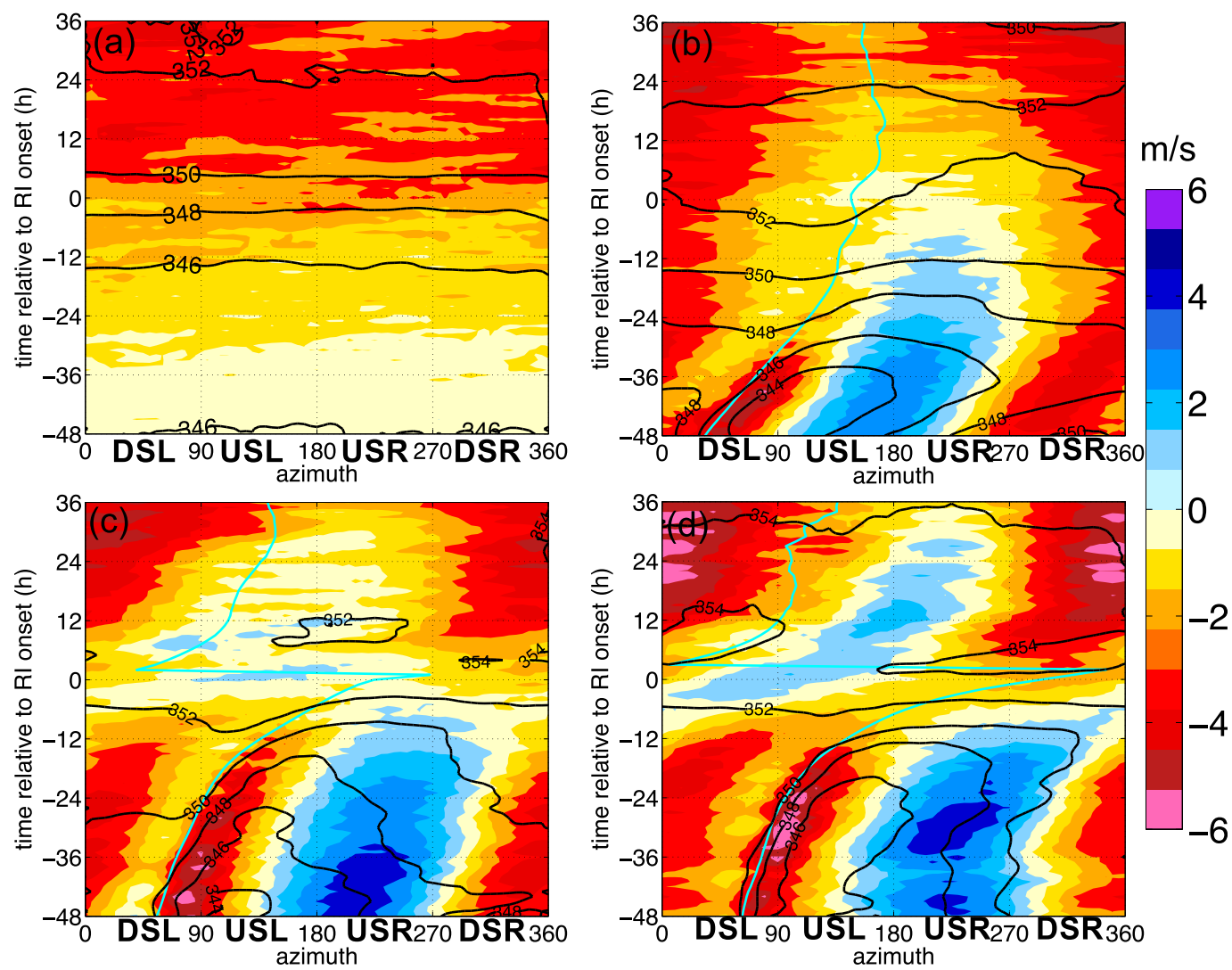

FIG. 9. Evolution of boundary layer radial flow (shading) averaged between RMW and RMW $+50 \mathrm{~km}$ below 2-km height along azimuth for (a) NOFLOW, (b) SH2.5, (c) SH5, and (d) SH6. Negative values for inflow, positive values for outflow. Cyan line indicates the tilt direction. Black contours are equivalent potential temperatures.

represents the amount of air to be lifted out of the boundary layer by the updrafts inside the $200-\mathrm{km}$ radius. Before the RI onset, the total radial mass flux is the smallest in NOFLOW, while SH5 and SH6 are comparable to each other. After RI onset, SH6 has the largest radial mass flux, while NOFLOW and $\mathrm{SH} 2.5$ become comparable. If we recall Figs. $2 \mathrm{a}-\mathrm{d}$ and Fig. 5 , the radial mass fluxes of the four sets after their RI onsets are consistent with the total kinetic energy and the wind field evolution that NOFLOW and SH2.5 have similar smaller vortex size and strength while SH6 has the largest size and strength.

In this section, we have shown the dynamical changes of the TC from large asymmetry before RI to smallest asymmetry at the RI onset and then reduced asymmetry during RI. From the analysis above, we can find that the adjustment in the secondary circulation is closely following the tilt vector. Also, it is found that shear is not always negative to the TC development that the shear induced convection at TC's outer core can spin up the wind field outside the inner core and expand the TC size. The vorticity budget analysis further demonstrates the critical role of deep down-tilt convection in sustaining and strengthening the mid- to upper-level vortices during the time of high vortex asymmetry.

\section{Evolution of thermodynamic structures}

The warm core is one of the thermodynamic structures that attracts a lot of attention from the TC community recently as it reflects the intensity of the TC system. Figure 11 shows the perturbation potential temperature $\theta^{\prime}$ (the difference between the $\theta$ at current and initial times) profiles above the surface TC center. For NOFLOW, a single warm anomaly is observed at $\sim 9-\mathrm{km}$ height from the beginning of simulation to near the onset time of RI. During RI, this warm anomaly extends upward to above $15-\mathrm{km}$ height and downward to the boundary layer (Fig. 11a). Before the RI onset, the structures of the warm anomaly at the TC center are similar in SH5 and SH6, but very different from NOFLOW. For SH5 and SH6, there are two distinct warm anomalies, one at midlevel $(5 \mathrm{~km})$ and the other at the upper troposphere $(11 \mathrm{~km})$. The midlevel warm anomaly gradually weakens at $\sim 12 \mathrm{~h}$ before the RI onset and merges with the upper-level warm anomaly at the RI 

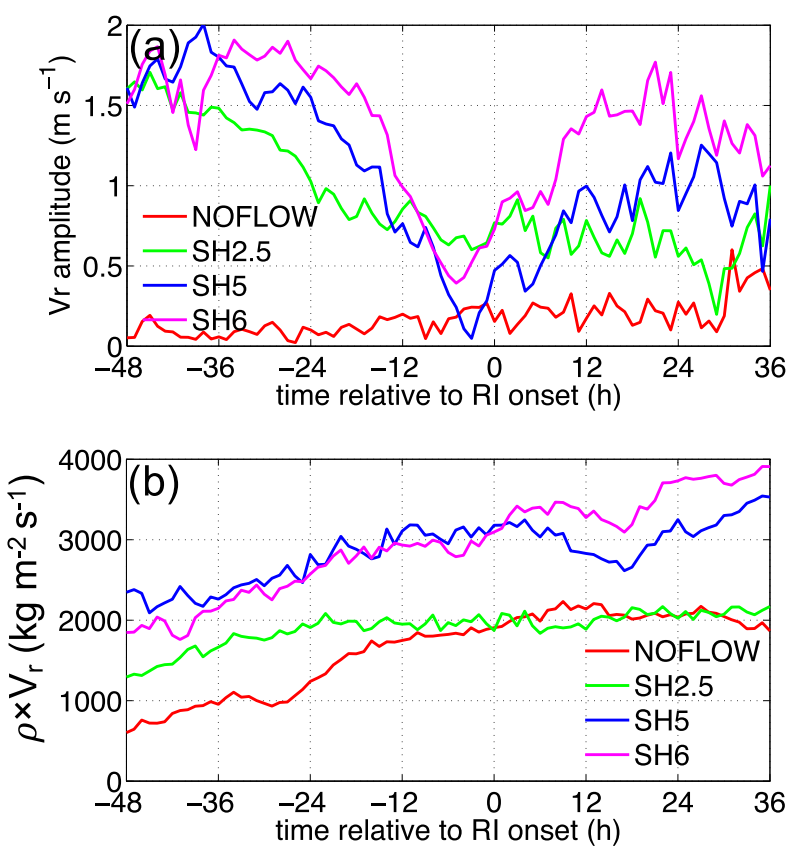

FIG. 10. Time evolution of (a) wavenumber-1 amplitude of boundary layer radial flow, and (b) total radial mass flux at $200-\mathrm{km}$ radius.

onset. After the RI onset, only one warm anomaly remains above the surface center (Figs. 11c,d). The warm anomaly (Fig. 11b) in the $\mathrm{SH} 2.5$ case shows an intermediate behavior between SH5/SH6 and NOFLOW. The midlevel warm anomaly at the $5-\mathrm{km}$ height is adjacent to the upper-level warm anomaly with no clear separation. Similar to SH5, the upper-level warm anomaly starts strengthening near the RI onset in $\mathrm{SH} 2.5$ as well. The locations and magnitudes of the warm core above the surface center are shown in Figs. 11e,f. The merging process of the two anomalies in SH5 and SH6 is indicated by the changes in the warm core altitude between -12 and $-6 \mathrm{~h}$ (Fig. 11f). During RI, the maximum warm anomalies in these four composites all descend from about $9 \mathrm{~km}$ at the beginning of RI to about $6 \mathrm{~km}$ during the later period of RI. The warm core magnitudes are monotonically increasing except for the period between -12 and $-6 \mathrm{~h}$ in SH5/SH6 (Fig. 11e), because of the shift in the location of the dominant warming area above the surface center (Fig. 11f).

To further construct a three-dimensional structure of the TC warm anomaly, the west-east $\theta^{\prime}$ cross section is plotted for NOFLOW and compared to the $\theta^{\prime}$ cross section along the tilt vectors for $\mathrm{SH} 2.5$, SH5, and SH6 in Fig. 12. The $\theta^{\prime}$ cross section from NOFLOW shows an axisymmetric structure. The upper-level warm anomaly is situated right above the surface center at $5-11-\mathrm{km}$ height long before the RI onset. In SH2.5, however, the warm anomaly is located slantwise toward the tilt direction at $-36 \mathrm{~h}$ with the upper-level warming anomaly (Fig. 12f) collocating with the primary updrafts (Fig. 6f). Once the upper-level vortex starts to align with the surface vortex, the upper-level warm anomaly detaches from convection and starts to align with the surface center, similar to NOFLOW (Fig. 12g). The $\theta^{\prime}$ field from SH5 exhibits two vertically separated maxima before the RI onset: one is located just above the surface center around 5-km height; the other is between 9 and $11 \mathrm{~km}$ which is displaced from the surface center but collocates with the upper-level convection. As the surface pressure change is a result of the air mass above, the displaced warming anomalies hinder the fast drop in the surface center pressure, which is known as one of the negative effects by the shear advection (Gray 1968). The midlevel warm anomaly reaches its peak strength at about $-12 \mathrm{~h}$, then weakens and dissipates afterward. Meanwhile, the upper-level warm anomaly gradually moves over the surface center and eventually becomes dominant throughout the vertical column after the RI onset. The merging of the two warm anomalies is associated with the timing of the vortex alignment.

To better illustrate the horizontal dynamic and thermodynamic structures at the upper level, we plotted the horizontal streamlines, potential temperature anomalies and simulated radar reflectivity at $z=9 \mathrm{~km}$ in Fig. 13 . NOFLOW develops a convective ring structure around the center with a clear eye at $-12 \mathrm{~h}$. This convective ring contracts and strengthens over time. The area with the maximum warming is always near the center. There is no dramatic structural change observed in the upper level for NOFLOW. For SH2.5, a transition from the completely down-tilt convection to a more axisymmetric convection structure occurs from $-36 \mathrm{~h}$ to the RI onset time. This transition takes place gradually, during which convection wraps around the surface center and forms a clear eye. In SH5 and SH6, the convection is concentrated inside a closed circulation at this level, acting as a moist envelope traveling around during the precession period from -36 to $-12 \mathrm{~h}$. The convection inside the circulation at the upper level is protected from the dry air outside in this structure because the environmental air is not circulated into the convection. At $-6 \mathrm{~h}$, the reflectivity weakens dramatically and decouples with the circulation at $9 \mathrm{~km}$ as the circulation center moves closer to the surface center. From $-6 \mathrm{~h}$, the maximum warming is decoupled from the high reflectivity (diabatic heating) area to move above the surface center. The RI onset time in SH5/SH6 starts at the most quiescent period for deep convections when the 9-km circulation aligns with the surface center. At $12 \mathrm{~h}$, we can observe a primary rainband structure in SH5 reflectivity and even clearer 

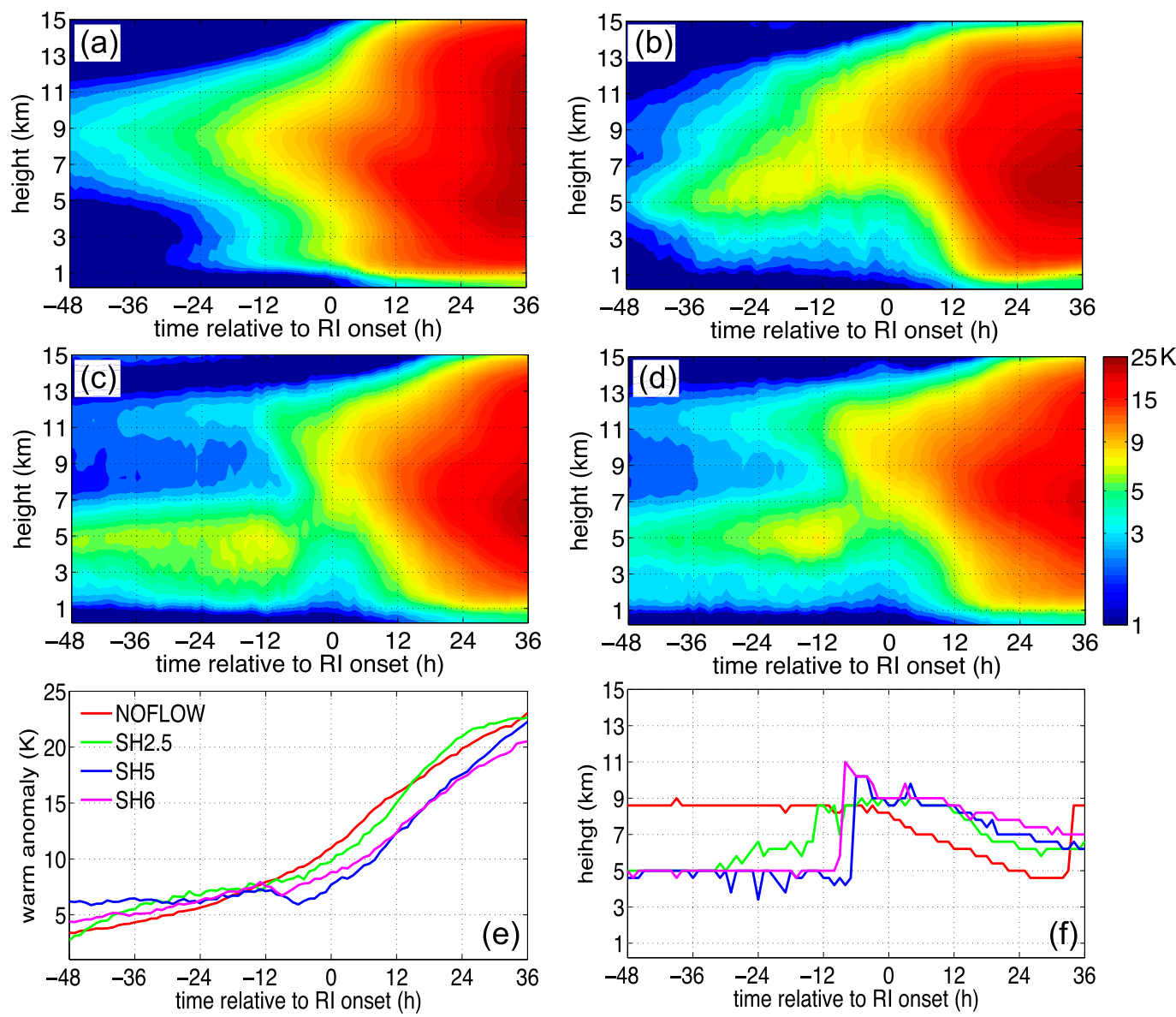

FIG. 11. Time-height plots for the potential temperature anomaly above the surface center: (a) NOFLOW, (b) SH2.5, (c) SH5, and (d) SH6. The maximum warm anomaly values and heights at each time are plotted in (e) and (f), respectively. The reference state for the potential temperature anomaly is the initial environmental potential temperature profile.

in SH6 while the reflectivity in NOFLOW and SH2.5 is more concentrated in the eyewall region. This primary rainband is responsible to the spin-up of the outer wind field, which could increase the possibility of secondary eyewall formation as discussed in Zhang et al. (2017).

In the same cross sections of perturbation potential temperature, the relative humidity $(\mathrm{RH})$ is also plotted to illustrate the moistening of the atmosphere (Fig. 12). In NOFLOW, the axisymmetric RH field shows that the moistening occurs around the vortex center at all times. The center RH at high levels starts to decrease greatly due to the higher temperature in the warm core and dry subsidence in the eye, which becomes more significant with time. In the three sheared cases, before the RI onset, the high RH field is completely following the updrafts, which indicates mid- to upper-atmospheric moistening by the convection. A sharp RH gradient at the edge of convection on the up-tilt side is seen at $-36 \mathrm{~h}$ in $\mathrm{SH} 2.5$, which becomes less clear at $-12 \mathrm{~h}$ due to the distribution of the convection. In SH5 and SH6, this sharp gradient lasts for longer time until $-6 \mathrm{~h}$ when the convection moves over the surface center. During the strong asymmetric period in all three sheared cases, the area above the surface center and on the up-tilt side is not moistened. At the RI onset time, convection is wrapping around the entire primary vortex which results in the high RH all around the surface center. Subsidence in the eye can bend the upper-level low RH contours downward resulting in a dry center above the $7-\mathrm{km}$ height from $-12 \mathrm{~h}$ in $\mathrm{SH} 2.5$ and $-6 \mathrm{~h}$ in SH5 and SH6. After the RI onset in SH5 and SH6, the asymmetry still exists and reflects on the RH field that the down-tilt side has been moistened more by the deeper and wider convection (Figs. 12o,t).

The azimuthal distribution of the reflectivity and $\mathrm{RH}$ averaged between RMW and RMW $+50 \mathrm{~km}$ using the 

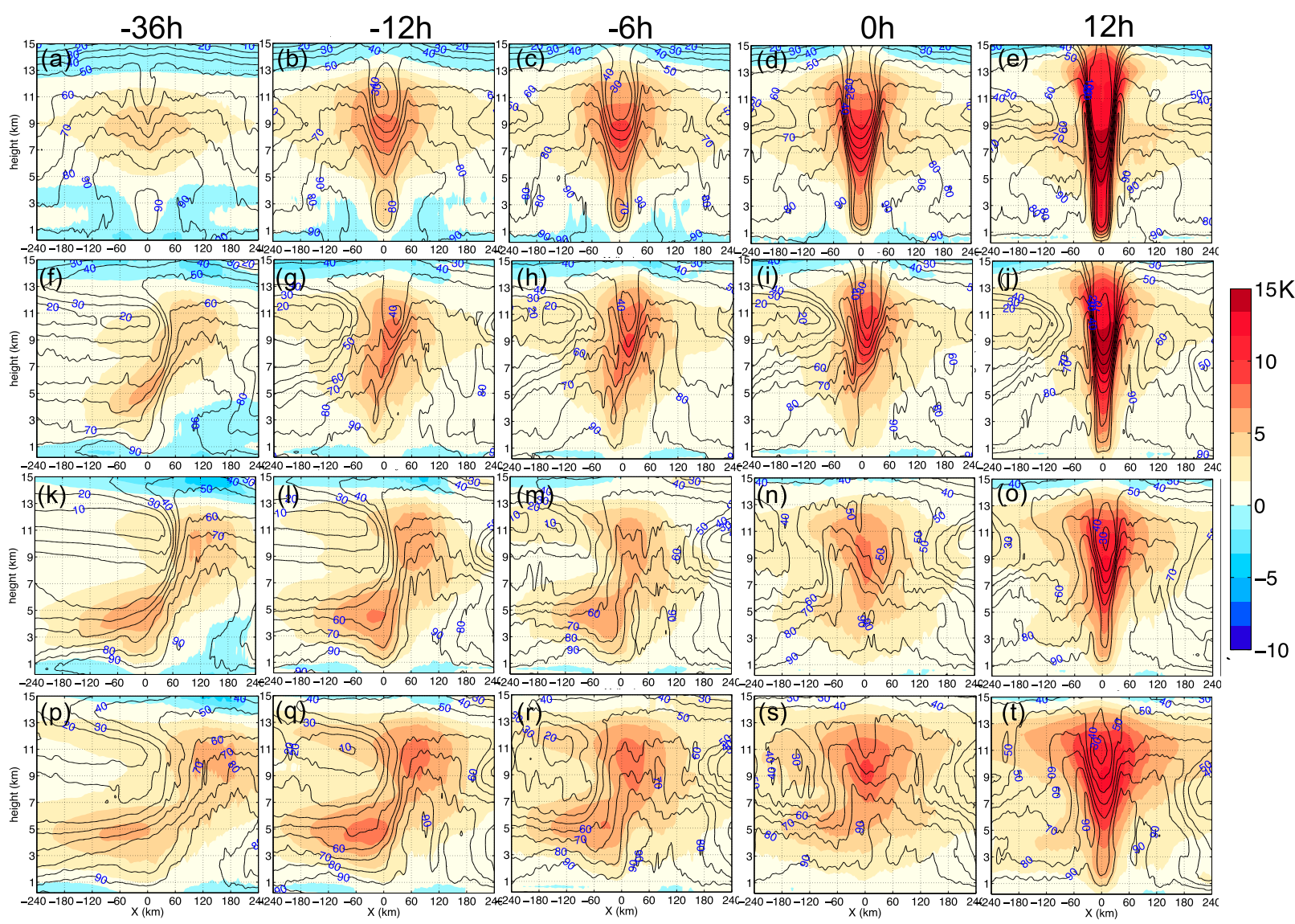

FIG. 12. Vertical cross-sectional plots of potential temperature anomaly (shading) and relative humidity (contour) along the tilt direction for (a)-(e) NOFLOW, (f)-(j) SH2.5, (k)-(o) SH5, and (p)-(t) SH6. The times are -36, -12, -6, 0, and $12 \mathrm{~h}$.

surface center are shown in Fig. 14 to exhibit the moistening in the atmosphere at different stages. The moistening by the convection before the RI onset in all azimuths is quite obvious in NOFLOW that the $\mathrm{RH}$ greater than $90 \%$ is up to $5-\mathrm{km}$ height. The reduction in $\mathrm{RH}$ after the RI onset is mainly due to the calculation method and a more concentrated eyewall during RI. The three sheared cases have similar distribution of reflectivity and $\mathrm{RH}$ along azimuth at $-36 \mathrm{~h}$. The SH2.5 case, however, distinguishes itself from SH5 and SH6 by spreading the reflectivity along more azimuth at much earlier time of $-12 \mathrm{~h}$. From Figs. 13g and 14g, it can be seen that the azimuthal occupancy of the convection at $-12 \mathrm{~h}$ is greatly enhanced by its smaller radial distance to the surface center and its wrapping around the center. The preconditioning of moisture in the downwind direction before the RI onset in SH5 and SH6 only happens at the very shallow boundary layer $(<3 \mathrm{~km})$. The mid- to upper-level RH increases only after the deep convection moves into the area. When the reflectivity spreads over all azimuth at the RI onset, the $\mathrm{RH}$ increases at all directions even with significantly reduced convection. After the RI onset, strong convection reforms the asymmetry in downshear-left and upshear-left quadrants, which diminishes in upshearright quadrant. The $\mathrm{RH}$ distribution again follows the high reflectivity area that the minimum $\mathrm{RH}$ value is on the right side of the environmental shear as the strong and deep convection locates on the left side of the shear.

The vertical diabatic heating profiles from -48 to $36 \mathrm{~h}$ are shown in Fig. 15 to further demonstrate the change of convective structure during this period. Each profile has both convective and stratiform components. The low-level diabatic heating in all four sets below $2 \mathrm{~km}$ is monotonically increasing with time which indicates increasing convective activity in this shallow layer. But the mid- to upper-level diabatic heating rate exhibits dramatic differences among the composites. The early diabatic heating profiles $(-48$ and $-36 \mathrm{~h})$ in the sheared composites are considerably larger at all levels than that in NOFLOW. The SH2.5 case builds a similar small diabatic heating rate to the NOFLOW case after the RI onset, while SH5 and SH6 have large upper-level diabatic heating rate during the most asymmetric time 

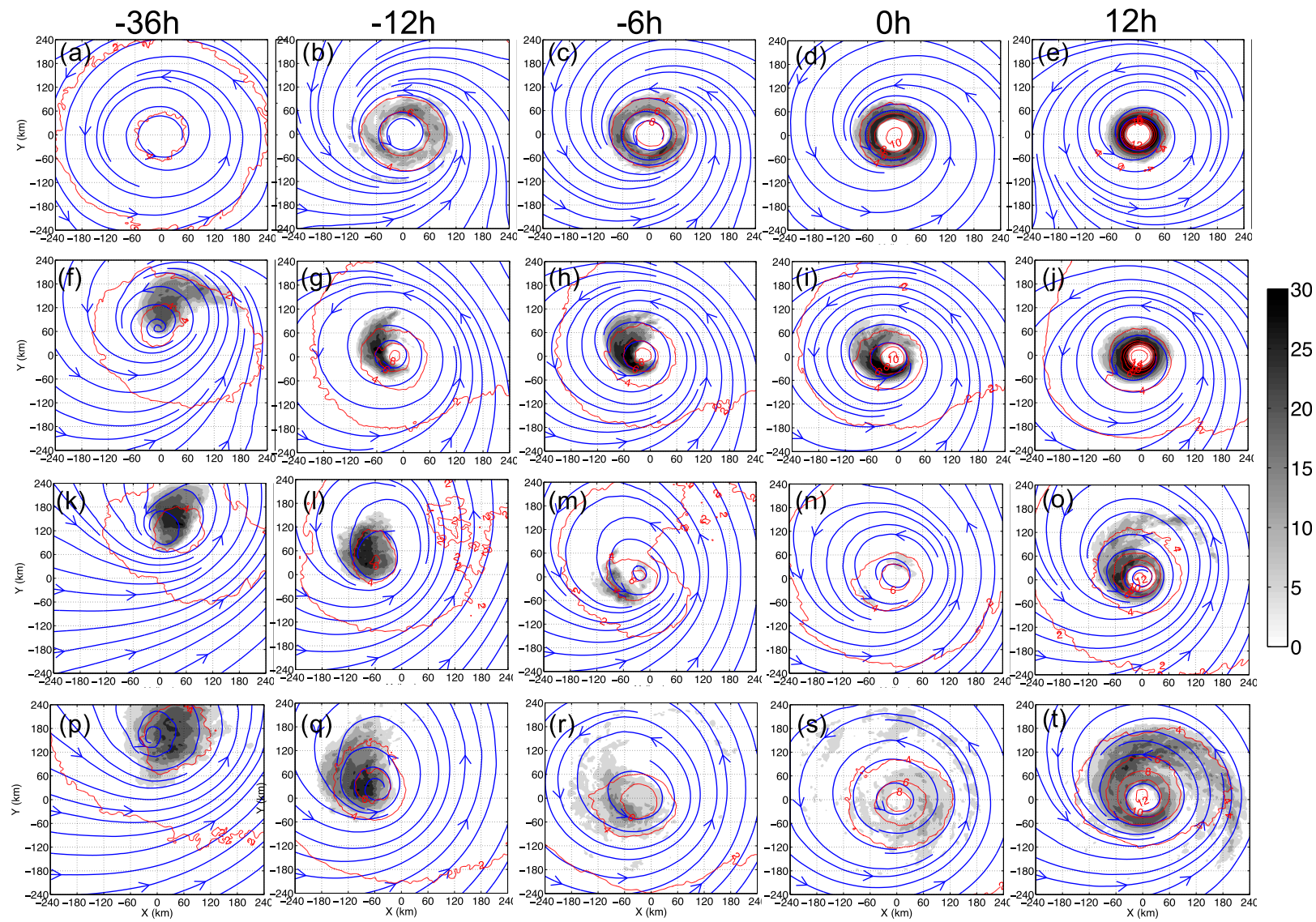

FIG. 13. Horizontal plots of simulated reflectivity (gray shading), warm anomaly (red contour), and streamlines (blue contour with arrows) at the 9-km height for (a)-(e) NOFLOW, (f)-(j) SH2.5, (k)-(o) SH5, and (p)-(t) SH6. The times are $-36,-12,-6,0$, and 12 h.

before $-24 \mathrm{~h}$ and during the RI. The $-6 \mathrm{~h}$ profiles in SH5 and SH6 have the smallest diabatic heating rate above 2-km height, while the RI onset profiles have the second smallest diabatic heating rate. The third and fourth rows of Fig. 6 show that this reduction in diabatic heating rates of SH5 and SH6 is mainly due to the reduction in updrafts. Given that $\theta_{e}$ of the boundary layer inflow does increase during this period (Figs. 9c,d), the reasons for this reduction in convective activity can be twofold: one is the decrease in tilt magnitude, and the other is the downdrafts occurring inside the updrafts. Near the onset of RI, the vortex column starts to become vertically aligned, which causes reduction in the downtilt preference for updrafts due to the reduction of tilt magnitude (Jones 1995). At the start of the vortex column alignment, convection wraps around the entire primary vortex center while downdrafts occur inside the updrafts such that no specific regions for updrafts and downdrafts are yet configured to accommodate deep convection, which thus diminishes in a manner similar to an ordinary supercell (Rotunno et al. 1988). Once the eyewall updrafts are established, dramatic increase occurs from -6 to $6 \mathrm{~h}$ in convective and especially upper-level stratiform diabatic heating. This heating profile evolution in Fig. 15 further confirms the transformation observed in reflectivity, updrafts/downdrafts before RI, near RI onset and during RI shown in Figs. 2e-h, Fig. 6, and Fig. 14.

\section{Summary and conclusions}

In this study, composite analyses of four sets of convection-permitting ensemble simulations are performed to show the dynamic and thermodynamic structures of TCs before, near, and during RI under different environmental shear conditions. By aligning ensemble members according to their RI onset times in each ensemble set, this composite analysis is able to reveal uniquely the common characteristics of TC vortices associated with RI onset.

In the NOFLOW case, all fields are presented in a quasi-axisymmetric way throughout the vertical levels since there is no persistent preference for any azimuthal direction with no environmental mean flow or shear. In 

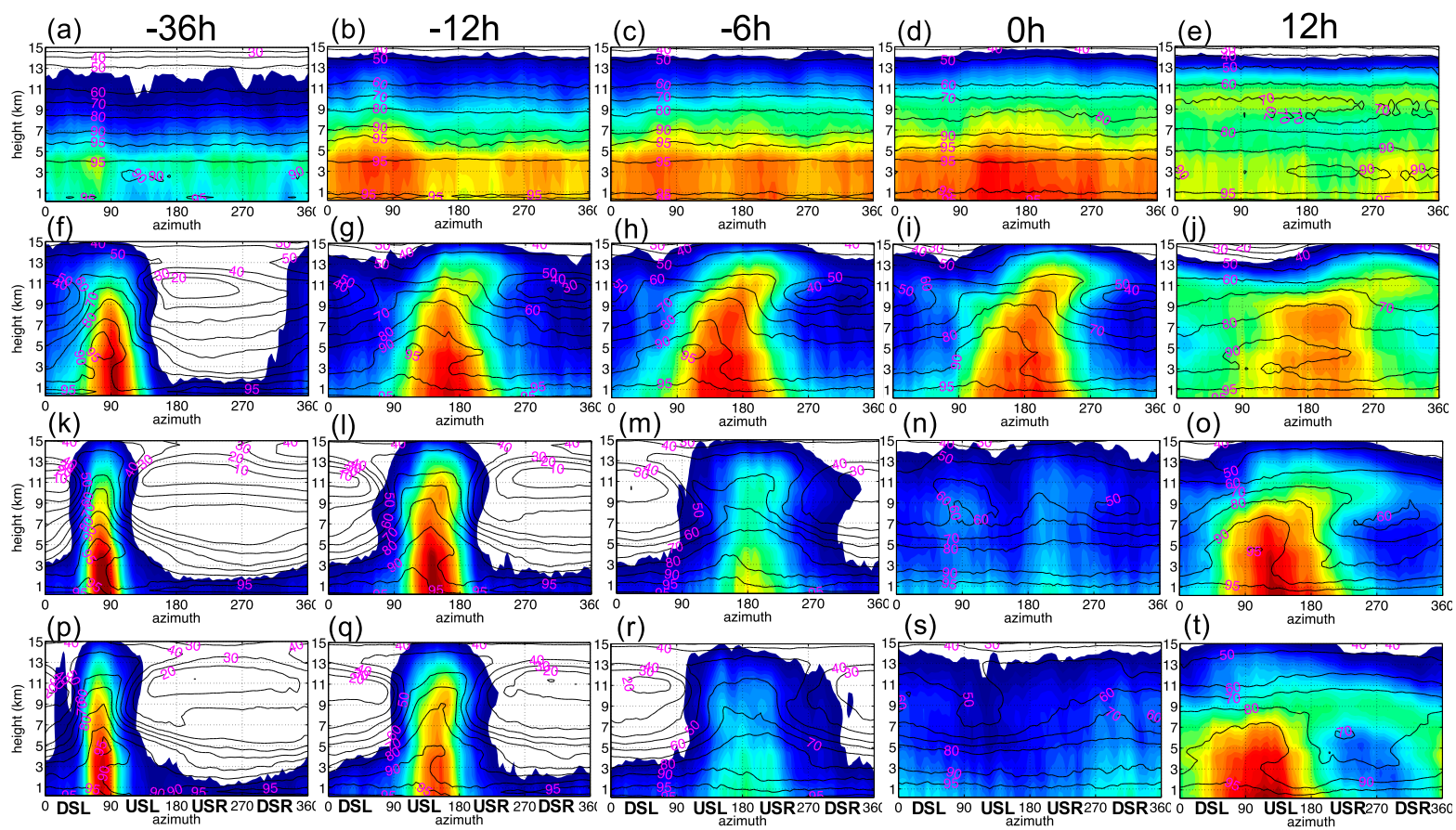

(q)

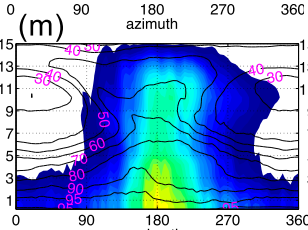

(n)

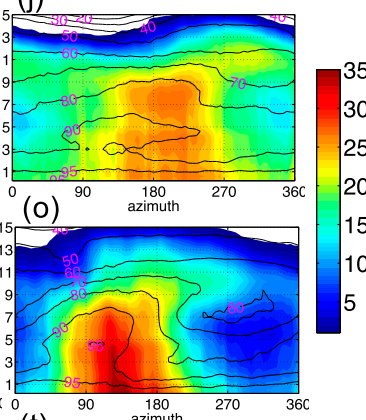

( $\mathrm{r})$
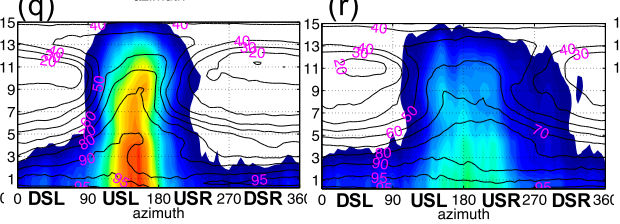

(s)

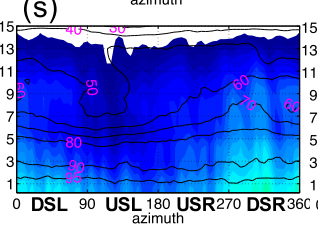

$(\mathrm{t})$

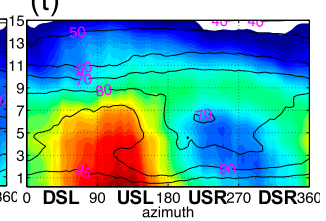

FIG. 14. Azimuth-height plots of relative humidity (black contour) and dBZ (shading) averaged between RMW and RMW $+50 \mathrm{~km}$ for (a)-(e) NOFLOW, (f)-(j) SH2.5, (k)-(o) SH5, and (p)-(t) SH6. The times are -36, -12, -6, 0, and $12 \mathrm{~h}$.

this case, a single warm anomaly sits above the surface center at all times, and the warming of upper-level vortex center is mainly due to subsidence. The subsidence in the eye not only generates center warming but also creates a dry region. The asymmetry amplitudes (Figs. 4b and 10a) from the three sheared cases (SH2.5, SH5, and SH6) decrease when time approaches the RI onset. In addition, both dynamic and thermodynamic fields are vertically aligned at the moment of the RI onset. The TC under small shear ( $\mathrm{SH} 2.5)$ displays intermediate behavior between SH5/SH6 and NOFLOW. There is no clear separation between mid- and upperlevel warm anomalies and the vortex column is more aligned during precession such that there exists an early development period before the actual RI starts. However, this early intensification is temporary, because the TC vorticity column and warm core is not yet fully aligned. This intensification period in $\mathrm{SH} 2.5$ before RI indicates that intensification can take place even when the vortex column has not completed its first cycle of precession, although this intensification is not as rapid and long-lasting as the RI that follows.

From the moderate shear cases (SH5 and SH6), we summarize that there are three stages of TC dynamic and thermodynamic structural evolution:

1) As summarized in Fig. 16a, before the RI onset, a strongly asymmetric vortex and convection structure displace the diabatic-heating-induced upper-level warm anomaly away from the midlevel warm anomaly, strong updrafts are concentrated at the down-tilt side, the boundary layer inflows are located beneath and to the upwind side of the updrafts while the boundary layer outflows are at the downwind side of the updrafts.

2) As summarized in Fig. 16b, approaching the RI onset time, the updrafts and downdrafts first alternatively spread over, wrap around the surface center and overlap with each other, which is followed by a temporal weakening of convection, the two warm anomalies gradually merge while the boundary layer radial flows become most axisymmetric.

3) As summarized in Fig. 16c, during RI, though there is still some asymmetry present, a small tilt magnitude enables the development of an eye structure, where strong updrafts are located in the eyewall region and downdrafts outside the eyewall as well as the subsidence in the eye.

The displaced mid- and upper-level warm anomalies (Fig. 16a) in stage 1 are also observed and simulated in Hurricane Eduard (2014) (Zawislak et al. 2016; Munsell et al. 2017) and in Hurricane Joaquin (2015) (Nystrom et al. 2018) before their RI onset. Stage 2, which is not well summarized in previous studies, is important for the RI onset that there are two adjustments happening during 

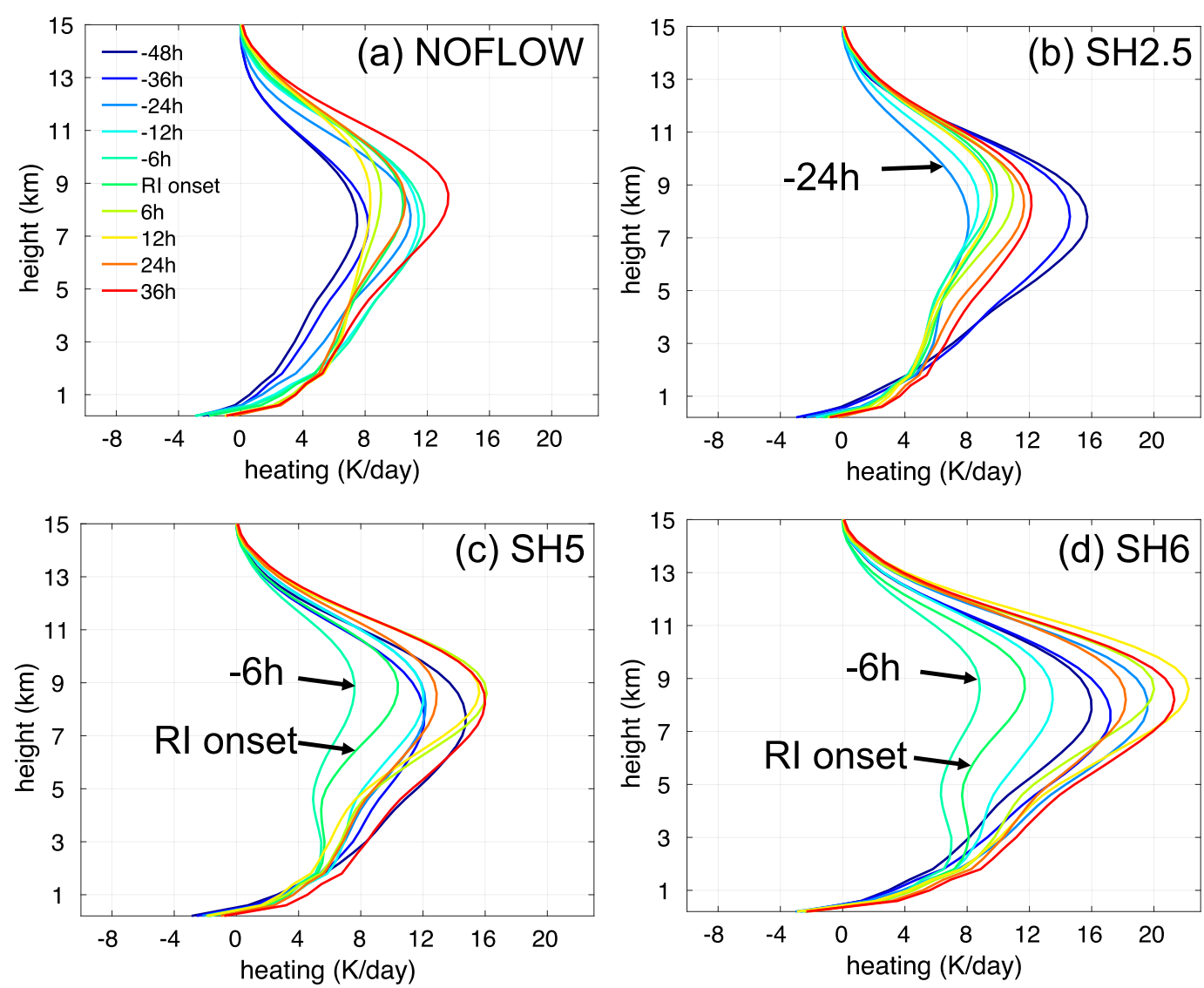

FIG. 15. Vertical diabatic heating profiles averaged in the $270 \mathrm{~km}$ by $270 \mathrm{~km}$ horizontal box for (a) NOFLOW,

(b) SH2.5, (c) SH5, and (d) SH6.

this period: one is the transition in the structure of updrafts/downdrafts; the other is merging of the two warm anomalies. These adjustments happen through the vortex alignment, which is a necessity to establish the structure of secondary circulation with an eye. The observational studies on Hurricane Earl (2010) (Stevenson et al. 2014; Rogers et al. 2015; Susca-Lopata et al. 2015) and Hurricane Eduard (2014) (Rogers et al. 2016) all confirm this necessity of axisymmetrization (Fig. 16b) for RI onset. The asymmetry does not disappear after the RI onset, but the new structure in Fig. 16c maintains the efficient structure of single upright warm core. The diagrams in Black et al. (2002) and DeHart et al. (2014) also showed the structure of stage 3. From a thermodynamic perspective, the RI onset is the time when the upper-level warm core aligns with the surface center, which changes the static stability of the atmosphere and more efficiently lowers the surface minimum sea pressure. Dynamically, it is the time when entire vortex column aligns and can initiate an efficient secondary circulation.

Besides the summarized three stages above, we also find the critical role of convection located on the down-tilt side under moderate shear on generating and sustaining the mid- to upper-level vorticity at earlier times before the RI onset. As seen from the domain summation of the diabatic heating rate when the TC vortex columns of SH5 and SH6 are strongly tilted (Figs. 2g,h), the convective activity is not interrupted by the low $\theta_{e}$ air in the boundary layer (Figs. 9c,d). With strong asymmetry, the low $\theta_{e}$ air from the convective downdrafts is then advected by the tangential wind toward the up-tilt side. In this asymmetric TC structure, the updrafts tend to start from smaller radii while hydrometeors fall at larger radii and down-wind side of the tilt vector, which in turn causes the boundary layer low $\theta_{e}$ air to be at the downstream of the updraft region. Before reaching the updrafts, the boundary layer low $\theta_{e}$ air is able to recover the temperature and moisture from the sea surface flux. This boundary layer air cycling is also shown in TZ14 and Zhang et al. (2013). Asymmetric convection persists that benefits thermodynamically from its asymmetry to entrain the recovered boundary layer air.

One other interesting finding is that the wind field size is closely related to the shear magnitude: the larger 


\section{(a) Before RI onset}

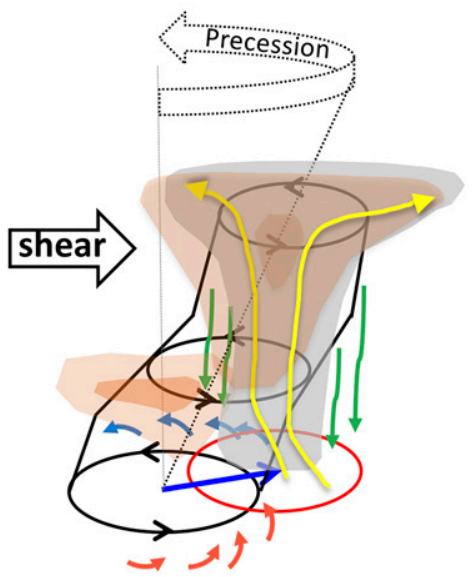

(b) Near RI onset

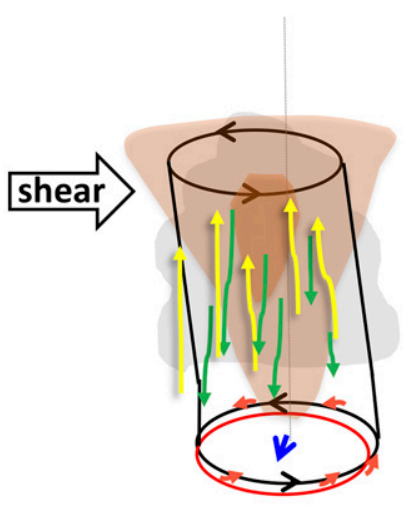

(c) After RI onset

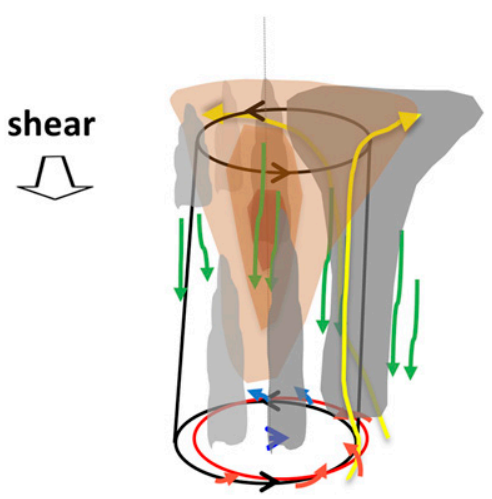

\section{Projection of mid/upper level vortex related positive vorticity at surface $\rightarrow$ Tilt Vector $\rightarrow$ Boundary layer inflow $\sim$ Boundary layer outflow Convection Warm anomaly $\downarrow$ Downdrafts $\uparrow$ Updrafts}

FIG. 16. Diagrams showing the convection, vortex column, and warm-core structure inside a TC's inner core under moderate vertical wind shear: (a) before RI onset, (b) near RI onset, and (c) after RI onset.

shear, the larger size of a TC. The outer wind fields in SH5 and SH6 are spun up by wider eyewall convection on the down-tilt side and the formation of the primary rainband, which enable the higher possibility of the secondary eyewall formation (Zhang et al. 2017). In SH6 the diabatic heating area is broader at the final stage and leads to more radially inward mass flux at large radii. Though the formation of outer rainband in SH5 and SH6 acts as a negative influence on the final intensity as discussed by Ying and Zhang (2012) that the angular momentum transportation to the inner core is disrupted by the inflow bypass into the rainband. With more convergence of air (Fig. 10b), the final vortex strength and size in SH5 and SH6 are larger than those in NOFLOW and SH2.5. In other words, environmental wind shear may be detrimental to TC intensity in terms of peak 10 -m surface wind speed but not necessarily the TC vortex strength in terms of storm-scale integrated kinetic energy.

In reality, however, it would be more complicated that the environmental factors (e.g., shear, SST, and dry air) are time evolving (e.g., Finocchio and Majumdar 2017) and have different three-dimensional structures (e.g., Onderlinde and Nolan 2014, 2016; Finocchio et al. 2016). Each adjustment to the hostile change in the environment would cause the cease of RI. Nevertheless, once the TC survives the adjustment, RI emerges. The warm anomaly structure is an intuitional estimate for the status of TC intensity. We can expect that any asymmetry due to the asymmetries in moisture (e.g., Braun et al. 2012), vertical wind shear studied here, the asymmetries in the surface interaction (e.g., land, SST distribution) would disturb the structure of the convection and hence distort the warming area, which can cease the RI. However, in our current study, only the sensitivity of a weak TC to the magnitudes of vertical wind shear is considered.

Acknowledgments. This work is partially supported by National Science Foundation under Grant 1712290 and by the Office of Naval Research under Grant N000141512298. Comments from three anonymous reviewers were very helpful. Computing was performed at the Texas Advanced Computing Center (TACC) where the model output is archived and can be made available freely upon request.

\section{REFERENCES}

Alland, J. J., B. H. Tang, and K. L. Corbosiero, 2017: Effects of midlevel dry air on development of the axisymmetric tropical cyclone secondary circulation. J. Atmos. Sci., 74, 1455-1470, https://doi.org/10.1175/JAS-D-16-0271.1.

Black, M. L., J. F. Gamache, F. D. Marks, C. E. Samsury, and H. E. Willoughby, 2002: Eastern Pacific Hurricanes Jimena of 1991 and Olivia of 1994: The effect of vertical shear on structure and intensity. Mon. Wea. Rev., 130, 2291-2312, https://doi.org/ 10.1175/1520-0493(2002)130<2291:EPHJOA>2.0.CO;2.

Braun, S. A., J. Sippel, and D. S. Nolan, 2012: The impact of dry midlevel air on hurricane intensity in idealized simulations with 
no mean flow. J. Atmos. Sci., 69, 236-257, https://doi.org/10.1175/ JAS-D-10-05007.1.

Chen, H., and D.-L. Zhang, 2013: On the rapid intensification of Hurricane Wilma (2005). Part II: Convective bursts and the upper-level warm core. J. Atmos. Sci., 70, 146-162, https://doi.org/ 10.1175/JAS-D-12-062.1.

— , and S. G. Gopalakrishnan, 2015: A study on the asymmetric rapid intensification of Hurricane Earl (2010) using the HWRF system. J. Atmos. Sci., 72, 531-550, https://doi.org/10.1175/JAS-D-14-0097.1.

DeHart, J. C., R. A. Houze, and R. F. Rogers, 2014: Quadrant distribution of tropical cyclone inner-core kinematics in relation to environmental shear. J. Atmos. Sci., 71, 2713-2732, https://doi.org/10.1175/JAS-D-13-0298.1.

Dunion, J. P., 2011: Rewriting the climatology of the tropical North Atlantic and Caribbean Sea atmosphere. J. Climate, 24, 893908, https://doi.org/10.1175/2010JCLI3496.1.

Elsberry, R. L., T. D. B. Lambert, and M. A. Boothe, 2007: Accuracy of Atlantic and eastern North Pacific tropical cyclone intensity forecast guidance. Wea. Forecasting, 22, 747-762, https://doi.org/10.1175/WAF1015.1.

Finocchio, P. M., and S. J. Majumdar, 2017: The predictability of idealized tropical cyclones in environments with time-varying vertical wind shear. J. Adv. Model. Earth Syst., 9, 2836-2862, https://doi.org/10.1002/2017MS001168.

- — - D. S. Nolan, and M. Iskandarani, 2016: Idealized tropical cyclone responses to the height and depth of environmental vertical wind shear. Mon. Wea. Rev., 144, 21552175, https://doi.org/10.1175/MWR-D-15-0320.1.

Gray, W. M., 1968: Global view of the origin of tropical disturbances and storms. Mon. Wea. Rev., 96, 669-700, https://doi.org/10.1175/ 1520-0493(1968)096<0669:GVOTOO>2.0.CO;2.

Harnos, D. S., and S. W. Nesbitt, 2011: Convective structure in rapidly intensifying tropical cyclones as depicted by passive microwave measurements. Geophys. Res. Lett., 38, L07805, https://doi.org/10.1029/2011GL047010.

Hendricks, E. A., M. S. Peng, B. Fu, and T. Li, 2010: Quantifying environmental control on tropical cyclone intensity change. Mon. Wea. Rev., 138, 3243-3271, https://doi.org/10.1175/ 2010MWR3185.1.

Jones, S. C., 1995: The evolution of vortices in vertical shear. Part I: Initially barotropic vortices. Quart. J. Roy. Meteor. Soc., 121, 821-851, https://doi.org/10.1002/qj.49712152406.

Judt, F., and S. S. Chen, 2016: Predictability and dynamics of tropical cyclone rapid intensification deduced from highresolution stochastic ensembles. Mon. Wea. Rev., 144, 43954420, https://doi.org/10.1175/MWR-D-15-0413.1.

Kaplan, J., and M. DeMaria, 2003: Large-scale characteristics of rapidly intensifying tropical cyclones in the North Atlantic basin. Wea. Forecasting, 18, 1093-1108, https://doi.org/10.1175/ 1520-0434(2003)018<1093:LCORIT>2.0.CO;2.

Miyamoto, Y., and T. Takemi, 2015: A triggering mechanism for rapid intensification of tropical cyclones. J. Atmos. Sci., 72, 2666-2681, https://doi.org/10.1175/JAS-D-14-0193.1.

— intensification in tropical cyclones as shown in a large ensemble of idealized simulations. J. Atmos. Sci., 75, 555-569, https://doi.org/10.1175/JAS-D-17-0177.1.

Munsell, E. B., F. Zhang, J. A. Sippel, S. A. Braun, and Y. Weng, 2017: Dynamics and predictability of the intensification of Hurricane Edouard (2014). J. Atmos. Sci., 74, 573-595, https://doi.org/ 10.1175/JAS-D-16-0018.1.

Nguyen, L. T., R. F. Rogers, and P. D. Reasor, 2017: Thermodynamic and kinematic influences on precipitation symmetry in sheared tropical cyclones: Bertha and Cristobal (2014). Mon. Wea. Rev., 145, 4423-4446, https://doi.org/10.1175/MWR-D17-0073.1.

Nolan, D. S., 2007: What is the trigger for tropical cyclogenesis? Aust. Meteor. Mag., 56, 241-266.

_ 2011: Evaluating environmental favorableness for tropical cyclone development with the method of point down-scaling. J. Adv. Model. Earth Syst., 3, M08001, https://doi.org/10.1029/ 2011MS000063.

_ - and E. D. Rappin, 2008: Increased sensitivity of tropical cyclogenesis to wind shear in higher SST environments. Geophys. Res. Lett., 35, L14805, https://doi.org/10.1029/2008GL034147.

Nystrom, R. G., F. Zhang, E. B. Munsell, S. A. Braun, J. A. Sippel, Y. Weng, and K. Emanuel, 2018: Predictability and dynamics of Hurricane Joaquin (2015) explored through convectionpermitting ensemble sensitivity experiments. J. Atmos. Sci., 75, 401-424, https://doi.org/10.1175/JAS-D-17-0137.1.

Onderlinde, M. J., and D. S. Nolan, 2014: Environmental helicity and its effects on development and intensification of tropical cyclones. J. Atmos. Sci., 71, 4308-4320, https://doi.org/10.1175/ JAS-D-14-0085.1.

_ helicity and the pathways to intensification in shear. J. Atmos. Sci., 73, 869-890, https://doi.org/10.1175/JAS-D-15-0261.1.

Rappin, E. D., and D. S. Nolan, 2012: The effect of vertical shear orientation on tropical cyclogenesis. Quart. J. Roy. Meteor. Soc., 138, 1035-1054, https://doi.org/10.1002/qj.977.

Reasor, P. D., M. T. Montgomery, and L. D. Grasso, 2004: A new look at the problem of tropical cyclones in vertical shear flow: Vortex resiliency. J. Atmos. Sci., 61, 3-22, https://doi.org/ 10.1175/1520-0469(2004)061<0003:ANLATP>2.0.CO;2.

_, R. Rogers, and S. Lorsolo, 2013: Environmental flow impacts on tropical cyclone structure diagnosed from airborne Doppler radar composites. Mon. Wea. Rev., 141, 2949-2969, https:// doi.org/10.1175/MWR-D-12-00334.1.

Riemer, M., M. T. Montgomery, and M. E. Nicholls, 2010: A new paradigm for intensity modification of tropical cyclones: Thermodynamic impact of vertical wind shear on the inflow layer. Atmos. Chem. Phys., 10, 3163-3188, https://doi.org/ 10.5194/acp-10-3163-2010.

Rios-Berrios, R., and R. D. Torn, 2017: Climatological analysis of tropical cyclone intensity changes under moderate vertical wind shear. Mon. Wea. Rev., 145, 1717-1738, https://doi.org/ 10.1175/MWR-D-16-0350.1.

Rogers, R. F., P. D. Reasor, and J. A. Zhang, 2015: Multiscale structure and evolution of Hurricane Earl (2010) during rapid intensification. Mon. Wea. Rev., 143, 536-562, https://doi.org/ 10.1175/MWR-D-14-00175.1.

_ J. A. Zhang, J. Zawislak, H. Jiang, G. R. Alvey, E. J. Zipser, and S. N. Stevenson, 2016: Observations of the structure and evolution of Hurricane Edouard (2014) during intensity change. Part II: Kinematic structure and the distribution of deep convection. Mon. Wea. Rev., 144, 3355-3376, https://doi.org/ 10.1175/MWR-D-16-0017.1.

Rotunno, R., J. B. Klemp, and M. L. Weisman, 1988: A theory for strong, long-lived squall lines. J. Atmos. Sci., 45, 463-485, https:// doi.org/10.1175/1520-0469(1988)045<0463:ATFSLL>2.0.CO;2.

Shu, S., F. Zhang, J. Ming, and Y. Wang, 2014: Environmental influences on the intensity changes of tropical cyclones over the western North Pacific. Atmos. Chem. Phys., 14, 6329-6342, https://doi.org/10.5194/acp-14-6329-2014.

Stevenson, S. N., K. L. Corbosiero, and J. Molinari, 2014: The convective evolution and rapid intensification of Hurricane 
Earl (2010). Mon. Wea. Rev., 142, 4364-4380, https://doi.org/ 10.1175/MWR-D-14-00078.1.

Susca-Lopata, G., J. Zawislak, E. J. Zipser, and R. F. Rogers, 2015: The role of observed environmental conditions and precipitation evolution in the rapid intensification of Hurricane Earl (2010). Mon. Wea. Rev., 143, 2207-2223, https://doi.org/ 10.1175/MWR-D-14-00283.1.

Tang, B., and K. Emanuel, 2010: Midlevel ventilation's constraint on tropical cyclone intensity. J. Atmos. Sci., 67, 1817-1830, https://doi.org/10.1175/2010JAS3318.1.

Tao, C., and H. Jiang, 2015: Distributions of shallow to very deep precipitation-convection in rapidly intensifying tropical cyclones. J. Climate, 28, 8791-8824, https://doi.org/10.1175/ JCLI-D-14-00448.1.

Tao, D., and F. Zhang, 2014: Effect of environmental shear, seasurface temperature, and ambient moisture on the formation and predictability of tropical cyclones: An ensemble-mean perspective. J. Adv. Model. Earth Syst., 6, 384-404, https://doi.org/ 10.1002/2014MS000314.

— and - 2015: Effects of vertical wind shear on the predictability of tropical cyclones: Practical versus intrinsic limit. J. Adv. Model. Earth Syst., 7, 1534-1553, https://doi.org/ 10.1002/2015MS000474.

Yaukey, P., 2014: Intensification and rapid intensification of North Atlantic tropical cyclones: Geography, time of year, age since genesis, and storm characteristics. Int. J. Climatol., 34, 10381049, https://doi.org/10.1002/joc.3744.
Ying, Y., and Q. Zhang, 2012: A modeling study on tropical cyclone structural changes in response to ambient moisture variations. J. Meteor. Soc. Japan, 90, 755-770, https://doi.org/10.2151/ jmsj.2012-512.

Zawislak, J., H. Jiang, G. R. Alvey, E. J. Zipser, R. F. Rogers, J. A. Zhang, and S. N. Stevenson, 2016: Observations of the structure and evolution of Hurricane Edouard (2014) during intensity change. Part I: Relationship between the thermodynamic structure and precipitation. Mon. Wea. Rev., 144, 3333-3354, https://doi.org/10.1175/MWR-D-16-0018.1.

Zhang, F., and D. Tao, 2013: Effects of vertical wind shear on the predictability of tropical cyclones. J. Atmos. Sci., 70, 975-983, https://doi.org/10.1175/JAS-D-12-0133.1.

, Y. Q. Sun, and J. D. Kepert, 2017: Dynamics and predictability of secondary eyewall formation in sheared tropical cyclones. J. Adv. Model. Earth Syst., 9, 89-112, https://doi.org/ 10.1002/2016MS000729.

Zhang, J. A., R. F. Rogers, P. D. Reasor, E. W. Uhlhorn, and F. D. Marks, 2013: Asymmetric hurricane boundary layer structure from dropsonde composites in relation to the environmental vertical wind shear. Mon. Wea. Rev., 141, 3968-3984, https:// doi.org/10.1175/MWR-D-12-00335.1.

Zhang, Y. J., Z. Meng, Y. Weng, and F. Zhang, 2014: Predictability of tropical cyclone intensity evaluated through 5-yr forecasts with a convection-permitting regional-scale model in the Atlantic basin. Wea. Forecasting, 29, 1003-1023, https://doi.org/ 10.1175/WAF-D-13-00085.1. 